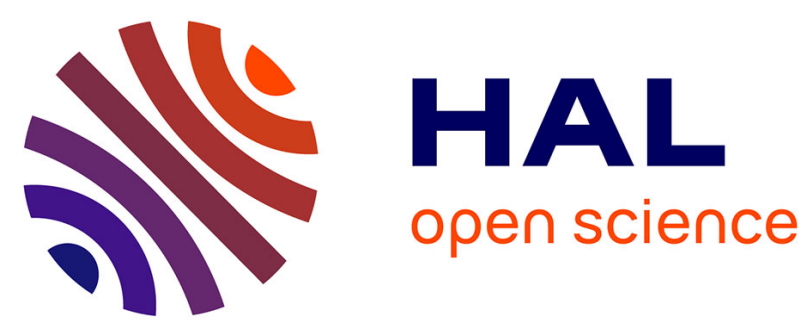

\title{
Conversion coating distribution on rough substrates analyzed by combining surface analytical techniques
}

Thomas Sanchez, Sandrine Zanna, Antoine Seyeux, Mélanie Vaudescal, Philippe Marcus, Polina Volovitch, Jolanta Światowska

\section{- To cite this version:}

Thomas Sanchez, Sandrine Zanna, Antoine Seyeux, Mélanie Vaudescal, Philippe Marcus, et al.. Conversion coating distribution on rough substrates analyzed by combining surface analytical techniques. Applied Surface Science, 2021, 556, pp.149734. 10.1016/j.apsusc.2021.149734 hal-03432886

\section{HAL Id: hal-03432886 https://hal.science/hal-03432886}

Submitted on 17 Nov 2021

HAL is a multi-disciplinary open access archive for the deposit and dissemination of scientific research documents, whether they are published or not. The documents may come from teaching and research institutions in France or abroad, or from public or private research centers.
L'archive ouverte pluridisciplinaire HAL, est destinée au dépôt et à la diffusion de documents scientifiques de niveau recherche, publiés ou non, émanant des établissements d'enseignement et de recherche français ou étrangers, des laboratoires publics ou privés. 


\title{
Conversion coating distribution on rough surfaces analyzed by combining surface analytical techniques
}

\author{
Thomas Sanchez ${ }^{\mathrm{a}}$, Sandrine Zanna ${ }^{\mathrm{a}}$, Antoine Seyeux ${ }^{\mathrm{a}}$, Mélanie Vaudescal $^{\mathrm{b}}$, Philippe Marcus ${ }^{\mathrm{a}}$, Polina \\ Volovitch $^{\mathrm{a}^{*}}$, Jolanta Światowska ${ }^{\mathrm{a}^{*}}$ \\ ${ }^{a}$ Chimie ParisTech-CNRS, PSL Research University, Institut de Recherche de Chimie Paris (IRCP), \\ 11 rue Pierre et Marie Curie, 75005 Paris, France \\ ${ }^{b}$ CNRS, Université de Bordeaux, PLACAMAT, UMS 3626 F-33600, Pessac, France
}

\begin{abstract}
In order to describe the chemical composition and the distribution of a thin trivalent chromium conversion coating on rough electrodeposited Zn-based alloy substrate, a methodology combining surface analytical and sputtering techniques was used. A sputtering by argon in glow discharge optical emission spectrometry (GD-OES) and by oxygen using time-of-flight secondary ion mass spectrometry (ToF-SIMS) were used to monitor the in-depth chemical composition evolution of the conversion coating and define the metal-conversion coating interface. Surface topography measurements were performed by high resolution 3D optical microscope. The chemical characterization of the conversion coating on the top surface and near the rough metal-oxide interface inside the craters was performed by X-ray photoelectron spectroscopy.

The local depth and composition of the conversion layer inside and outside the craters were performed by Auger electron spectroscopy nanoprobe equipped with coaxial detector to prevent from shadowing effect during measurement. The results indicated inhomogeneous sputtering inside the ToF-SIMS craters, which was attributed to the shadowing effect, caused by the roughness of the substrate and the $45^{\circ}$ incidence angle ion gun. GD-OES sputtering appeared homogeneous in different areas inside the crater despite the roughness of the substrate, which was attributed to the perpendicular incidence angle of the sputtering.
\end{abstract}

Keywords: ZnNi alloy; thin $\mathrm{Cr}(\mathrm{III})$ conversion coating; buried interfaces; sputtering; shadowing effect

\section{Corresponding authors:}

Polina Volovitch (polina.volovitch@chimieparistech.psl.eu), and

Jolanta Światowska (jolanta.swiatowska@chimieparistech.psl.eu) 


\section{Introduction}

Zinc alloys are known to provide good corrosion protection to ferrous-based alloys, forming a barrier layer and serving as sacrificial anodes [1]. Among different zinc alloys, $\mathrm{Zn}-\mathrm{Ni}$ alloy is used for specific applications due to its good mechanical properties [2]. The $\mathrm{Zn}-\mathrm{Ni}$ alloys show the highest corrosion resistance for a monophasic alloy with Ni content of 12-14 wt.\% [3]. In order to enhance the corrosion resistance of the $\mathrm{Zn}-\mathrm{Ni}$ alloys, thin conversion coatings (usually an oxide layer of 25-45 $\mathrm{nm}$ thickness) are often used to passivate the surface and/or to improve the paint adhesion $[4,5]$. Among them, chromate conversion coatings offer excellent corrosion protection properties related to a "self-healing" effect of $\mathrm{Cr}(\mathrm{VI})[6]$. However, chromates were proved to be genotoxic and carcinogen [7] and, since 2006, European legislation has tried to tackle hexavalent chromium via Registration, Evaluation, Authorization and Restriction of Chemicals (REACh) and Restriction of the use of certain Hazardous Substances (RoHS) [8]. According to these legislations, the application of $\mathrm{Cr}(\mathrm{VI})$ compounds will be banned in Europe. Therefore, the development and the optimization of new chromate-free conversion coating is strongly required $[9,10,11]$. One of the most promising candidates to replace $\mathrm{Cr}(\mathrm{VI})$ conversion coatings are $\mathrm{Cr}(\mathrm{III})$-based conversion coatings [12].

In order to better understand the formation and the corrosion protection properties of trivalent chromium conversion coatings on zinc-nickel alloys, they were studied by electrochemical methods and atmospheric corrosion tests $[13,14]$. However, only few studies have been focused on a more detailed chemical characterization of trivalent chromium conversion coatings on electrodeposited rough zinc-alloy substrates [15], especially in the case of thin conversion coatings $[16,17]$. The challenges for the study of such a system is related not only to their complex chemistry but also to the significant roughness of the substrate and the difficulties to reveal buried interfaces for chemical analysis. Such systems require the development of specific methodological characterization approach in order to overcome the gap between the micrometric roughness of the electrodeposited Zn-based alloy and the nanometric thickness of the chromium conversion coating.

X-ray photoelectron spectroscopy (XPS) is widely used for nanometric oxides characterization because of its outmost ability to examine and quantify the surface chemical composition [18]. It can be used in parallel with depth profiling techniques such as glow discharge optical emission spectrometry (GD-OES) [19] and time-of-flight secondary ion mass spectrometry (ToF-SIMS) [20]. Although no common strategy was defined to perform this type of characterization, it appears that the coupling between ion beam sputtering and XPS offers a better understanding of the in-depth composition of the thin oxide layers [21].

The combination of XPS and ToF-SIMS measurements was previously applied for studies of buried interfaces in the case of $\mathrm{Zr}$-doped $\mathrm{NiAl}$ coating on a nickel-based superalloy [22], on conversion coatings on aluminium alloy [23] and passive films on duplex stainless steel [24]. In the case of polished smooth metallic substrates with presence of thin oxide layers, the ion-depth profiles for which a gradual increase and decrease of the signals of the species characteristic of the coating/passive layer and the substrate, respectively, can be observed [25]. The ToF-SIMS can however sputter only at limited depth and the use of low angle incidence ion beam in ToF-SIMS $\left(45^{\circ}\right)$ can impede analysis of rough substrates due to topographical effects.

Recently, the combination of GD-OES and XPS analysis to obtain a detailed chemical description of the surface chemistry at different depths of a multi-layer system was proposed $[26,27]$. One of the 
advantages of the GD-OES is the high depth resolution with high etching rate [28]. The other advantage is a normal direction of the argon beam to the sample surface, which prevents from the shadowing effect in the crater generation [29]. Nonetheless, it was previously demonstrated that near zenithal ion etching can induce a roughness increase and therefore limit the depth resolution $[30,31]$. This effect was indeed reported during argon plasma sputtering by GD-OES profiling [32,33]. In addition, extreme surface perturbation in the GD-OES crater were reported, especially redeposition of species on the border of the crater and high temperature leading to burns or melting processes at the surface. The plasma parameters should be carefully adjusted for each system. The principle of GD-OES sputtering relying on a Grimm-type gas flow for the injection of argon in the plasma chamber, the gas nature (argon, argon-oxygen mixture, argon-nitrogen mixture, etc.), pressure and power control are the key parameters to consider in order to obtain a homogeneous sputtering in the crater [34]. GD-OES is however unable to perform accurate localized sputtering, the minimum diameter of the crater in the existing systems being $2 \mathrm{~mm}$.

To verify the local chemical composition in the crater and the local residual thickness of the studied layer, Auger electron spectroscopy nanoprobe (Nano-AES) combined with argon beam in the analytical chamber [35] seems of interest. The great interest of AES relies on its sensitivity to the extreme surface and the possibility of the localized analysis with resolution of several nanometers [36]. The combination of nano-AES with an argon ion beam allows to perform local in-depth chemical profiling of the surface in the model craters [37]. Nonetheless, sputtering rate by the argon ion beam might still be affected by local surface chemistry and the detection can be limited by surface topography [38,39]. The use of normal ion etching and the geometry of cylindrical mirror analyzer (CMA) mounted coaxially with respect to the incident electron beam seems to be the best solution to improve sensitivity [36] and reduce the shadowing effects for surfaces with complex topography [40].

In this paper, in order to characterize the chemistry of the top surface of the coating and near the coating-substrate interface of a thin trivalent chromium conversion coating on rough electrodeposited Zn-based alloy, we combine GD-OES and ToF-SIMS sputtering with XPS and nano Auger characterization. The crater morphology was also analyzed by high resolution 3D optical microscopy. The main purpose of this study was to combine different analysis and sputtering modes using spectroscopic techniques in order to describe the chemical composition and 3D distribution for thin oxide layers on rough substrates. The novelty of this characterization resides in the combination of an ion etching (using GD-OES or ToF-SIMS) and XPS analysis with a third local profiling technique (nano Auger), which enables to verify the influence of the sputtering mode (low incidence ionetching by ToF-SIMS and orthogonal low energy argon plasma GD-OES sputtering) on rough electrodeposited surfaces on the homogeneity of sputtering. 


\section{Experimental}

\subsection{Materials}

\subsubsection{Zn-Ni alloy with chromium conversion coating}

The samples consisted of electrodeposited $\mathrm{Zn}-\mathrm{Ni}$ alloy treated with thin trivalent chromium conversion coating. First, steel plates of $10 \times 15 \mathrm{~cm}^{2}$ used as substrates were degreased, grit-blasted and electrodeposition was performed in alkaline 12-16 \% Zn-Ni bath for 45 minutes at $3 \mathrm{~A} / \mathrm{dm}^{2}$. After electrodeposition, samples were rinsed with deionized water for 10 minutes and dipped in trivalent chromium passivation bath then rinsed for 3 minutes in deionized water and dried with pressurized air. Relief-baking of the samples was performed at around $200{ }^{\circ} \mathrm{C}$ for $20 \mathrm{~h}$ to alleviate hydrogen embrittlement. X-ray fluorescence (XRF) showed that the deposited $\mathrm{ZnNi}$ was of $18 \pm 2 \mu \mathrm{m}$ in thickness and $14 \pm 2$ \%at. of nickel. X-ray diffraction (XRD) showed only the presence of the gamma phase $\left(\mathrm{Zn}_{21} \mathrm{Ni}_{5}\right)$.

For all the following tests, $2 \times 2 \mathrm{~cm}^{2}$ samples were cut from the central part of each $15 \times 10 \mathrm{~cm}^{2}$ plate to avoid the edge effects observed in electrodeposition process.

\subsubsection{Model $\mathrm{Zn}(\mathrm{OH})_{2}$ ALD layer}

A reference zinc oxide thin film sample (with a thickness of few micrometers) for XPS analysis was prepared by atomic layer deposition (ALD) on (0001) silicon wafer. ALD was performed at low temperature of $80{ }^{\circ} \mathrm{C}$ following the conditions used for preparation of doped $\mathrm{ZnO}$ films for semiconductors [41]. Following the $\mathrm{ZnO}$ deposition, the $\mathrm{ZnO}$ layer was hydrated during one week in a humid chamber (relative humidity $85 \%$, temperature $20^{\circ} \mathrm{C}$ ) to form the $\mathrm{Zn}(\mathrm{OH})_{2}$.

\subsection{Morphological and chemical characterizations}

\subsubsection{Morphological characterization}

Optical characterization of the samples was performed using a Keyence VHX-5000 microscope equipped with the VH-Z500T objective allowing for magnification from 500x to 5000x. With 500x magnification, the area of view was of $610 \times 457 \mu \mathrm{m}^{2}$ for a $2000 \times 1600 \mathrm{px}$ image. Stitching was performed for wider area image acquisition. Thanks to its short depth of field $(<0.5 \mu \mathrm{m})$, multiple images with different objective-to-sample distance were taken in order to obtain a threedimensional image of the surface [42]. It was performed by a stitching of twenty-five 3D-composition images at 500x magnification over $2.8 \times 2.3 \mathrm{~mm}^{2}$. Each 3D-composition was computed from 100 images over 50 microns in depth. High resolution images were obtained by 3D-composition with 2000x magnification.

In addition to the in-depth composition of images, the Keyence VHX-5000 microscope records the height of each focused pixel and therefore allow a topographic measurement of the surface. The height cartography was converted to an 8-bit grey nuance image and the roughness parameters were calculated using Gwyddion software version 2.50 [43]. 


\subsubsection{Chemical characterization of the thin oxide layer}

The methodological approach for in-depth chemical description on the conversion coating is presented in the Fig. 1. First, the initial top surface was characterized by XPS (Fig. 1a, see details in section 2.2.3). Then, thanks to the full depth profiles performed by GD-OES and ToF-SIMS, the time necessary to sputter $80 \%$ of the initial thickness of the conversion coating was defined (see section 2.2.4) and the craters were prepared by GD-OES and ToF-SIMS sputtering to remove of $80 \%$ of the initial conversion coating thickness (Fig. 1b, see details in section 2.2.4). Then, the general chemical surface characterization inside the crater was performed by XPS (Fig. 1c, details in section 2.2.3) and the distribution of the remaining conversion coating inside the crater was verified by nano-Auger (Fig. 1d, see section 2.2.5 for details).

\subsubsection{XPS}

XPS analysis was performed (Fig. 1a) with a Thermo Electron Escalab 250 spectrometer, using a mono-chromated Al Ka X-ray source $(h v=1486.6 \mathrm{eV})$. The base pressure in the analytical chamber was maintained at $10^{-9} \mathrm{mbar}$. The spectrometer was calibrated using $A u 4 \mathrm{f}_{7 / 2}$ at $84.1 \mathrm{eV}$. The take-off angle was $90^{\circ}$. A $500 \mu \mathrm{m} \mathrm{X-ray} \mathrm{spot} \mathrm{size} \mathrm{was} \mathrm{used.} \mathrm{Survey} \mathrm{spectra} \mathrm{were} \mathrm{recorded} \mathrm{with} \mathrm{a} \mathrm{pass} \mathrm{energy}$ of $100 \mathrm{eV}$ with a step size of $1 \mathrm{eV}$ and high-resolution spectra of the $\mathrm{C} 1 \mathrm{~s}, \mathrm{O} 1 \mathrm{~s}, \mathrm{Zn} 2 \mathrm{p}, \mathrm{Cr} 2 \mathrm{p}$, Ni 2p, Zn LM2 and N 1s regions were recorded with a pass energy of $20 \mathrm{eV}$ and a step size of $0.1 \mathrm{eV}$. To compensate the charge effect, a $1 \mathrm{eV}$ flood-gun was used on the sample and the analyzed spot was centered as close as possible to the mount contact. The data analysis was performed with the CasaXPS software version 2.3.17PR1.1 using an iterative spline-Shirley-type background subtraction. Symmetrical peaks (Gaussian $70 \%$ - Lorentzian $30 \%$ ) were used for fitting except for the $\mathrm{Cr} 2 \mathrm{p}$ where a corrected fit describing $\mathrm{Cr} 2 \mathrm{p}$ multiplet was used as described in previous work [44]. Charge correction of the spectra was performed with reference to $C$ 1s peak of adventitious carbon (C-C/CH) peak at $285 \mathrm{eV}$. It should be noted that this calibration method should be done with a lot of precautions due to the possibility of important discrepancy in binding energies for non-conductive samples showing significant charging effect as discussed by Greczynski et al. [18].

The presence of $Z n$ Auger peaks in the $\mathrm{Cr} 2 p$ region $\left(L_{3} M_{23} M_{45}\left({ }^{1} P\right)\right.$ and $\left.L_{3} M_{23} M_{45}\left({ }^{3} P\right)[45,46]\right)$ was considered for spectra decomposition on chromium passivated $\mathrm{ZnNi}$. The analysis of model reference zinc hydroxide sample was performed to allow a quantitative decomposition of the $\mathrm{Cr} 2 \mathrm{p}$ region. This reference sample was the zinc oxide thin film deposited on Si substrate by ALD and aged in humid chamber to form the zinc hydroxide as described above in section 2.1.2.

\subsubsection{ToF-SIMS and GD-OES}

Time-of-flight secondary ion mass spectrometry (ToF-SIMS) analysis was performed using an ToFSIMS 5 spectrometer (ION TOF GmbH, Münster, Germany) operating at a pressure of $10^{-9}$ mbar. A pulsed $25 \mathrm{keV} \mathrm{Bi}^{+}$primary ion source delivering $1.2 \mathrm{pA}$ of target current over a $100 \times 100 \mu^{2}$ area was used for analysis. The secondary ions $\mathrm{ZnO}^{-}, \mathrm{Ni}_{2}{ }^{-}$and $\mathrm{CrO}_{2}{ }^{-}$characteristic of zinc oxides, metallic nickel and chromium oxides species, respectively, were considered. Depth profiles were obtained by interlacing the primary gun with a $2 \mathrm{keV} \mathrm{Cs}^{+}$sputter beam delivering $130 \mathrm{nA}$ of target current over a $300 \times 300 \mu \mathrm{m}^{2}$ area ( $45^{\circ}$ incidence angle to the specimen surface). For the depth profiles, the 
intensity of the ionized fragments, all measured quasi-simultaneously, were plotted $v s$ the $\mathrm{Cs}^{+}$ion sputtering time. The signal intensity was reported using a logarithmic scale. Data acquisition and post processing analysis were performed using the SurfaceLab software version 6.5 .

Glow-discharge optical emission spectroscopy (GD-OES) was performed with a Horiba GD-Profiler $2^{\text {TM }}$ fueled by Arcal 1 argon from Air Liquide. The plasma conditions, power-chamber pressure were optimized to obtain homogeneous sputtering with $800 \mathrm{~Pa}$ and $30 \mathrm{~W}$ argon plasma with a $4 \mathrm{~mm}$ diameter anode. The intensities of the 46 wavelengths calibrated in the polychromator were recorded simultaneously during the argon plasma sputtering at a rate of one hundred points per second. Among them, the emission wavelength corresponding to carbon, oxygen, chromium, iron, nickel and zinc were considered. The intensities were normalized to the total emitted light in the plasma so that it reflected the variation of the in-depth concentrations of the considered elements and reported as a function of sputtering time. As for the analysis of ToF-SIMS ion profiles, nickel signal was used as a marker of the conversion coating to $\mathrm{ZnNi}$ alloy substrate interface.

In order to reveal the metal-oxide interface, sputtering of the conversion coating was performed using either GD-OES or ToF-SIMS technique (Fig. $\mathbf{1} \mathbf{b}$ and $\mathbf{c}$ ). For both techniques, prior to the generation of the crater in the conversion coating, elemental in-depth profiles were acquired in 4 different areas of the $10 \times 15 \mathrm{~cm}^{2}$ plate. The thickness of the conversion coating (in sputtering time) was determined as the sputtering time corresponding to the increase of $\mathrm{Ni}$ signal, which is a marker of the $\mathrm{ZnNi}$ alloy. Subsequently, the defect generation was performed on a $2 \times 2 \mathrm{~mm}^{2}$ sample cut from the same plate. Sputtering was stopped at $80 \%$ of the measured sputtering time corresponding to conversion coating thickness to let the $\mathrm{ZnNi}$ alloy underneath preserved.

For the crater generation by ToF-SIMS (Fig. 1c), in order to avoid the effect of cesium and bismuth implantation on the chemistry of the conversion coating, the sputtering was performed with oxygen $\left(\mathrm{O}_{2}^{-}\right)$ion source at $2 \mathrm{keV}$ acceleration voltage delivering $100 \mathrm{nA}$ of target current over a $30 \times$ $30 \mathrm{\mu m}^{2}$ area and the analysis primary $\mathrm{Bi}^{+}$ion gun was set off. For the crater generation by GD-OES, low sputtering rate was chosen to have a better control on the crater depth. The plasma conditions were set to $650 \mathrm{~Pa}$ and $8 \mathrm{~W}$ argon plasma with a $2 \mathrm{~mm}$ in diameter anode.

XPS analysis was performed in the generated craters subsequently to its formation to obtain near metal-oxide chemical description (Fig. 1d).

\subsubsection{Nano Auger}

Auger electron spectroscopy was performed using a PHI 710Xi Auger nanoprobe equipped with a cylindrical mirror analyzer (CMA) mounted coaxially with respect to the electron column. Thanks to this particular system geometry, the take-off angle of the analyzed Auger electrons is below $30^{\circ}$ from the primary electron beam and thus permits to avoid shadowing effect. The pressure in the analysis chamber was maintained between $10^{-10}$ and $10^{-9}$ mbar. The electron beam was set normal to the surface, at $10 \mathrm{keV}$ accelerating energy and $10 \mathrm{nA}$ current to obtain approximately $20 \mathrm{~nm}$ spot size. Specific zones of a few micron-square were selected for scanning and spectra acquisition in order to optimize the signal intensity to noise ratio and limit the charge effect of the surface. Spectra were acquired in direct mode with a step size of $3 \mathrm{eV}$. The C KLL, O KLL, Cr LMM, Ni LMM and Zn LMM peaks were considered. Spectra fitting was performed with the in-built PHI-Ulvac MultiPak software 
using a Shirley-type background subtraction. In our case, in-depth composition profiles were performed by combining Auger electron spectroscopy and normal argon ion gun sputtering thanks to eucentric rotation. The ion gun was set at $2 \mathrm{kV}$ acceleration voltage and $1 \mu \mathrm{A}$ current on a $2 \times 2 \mathrm{~mm}^{2}$ surface. The sputtered depth was calibrated on $\mathrm{SiO}_{2}$ substrate prior to the measurements. The ion gun sequence was set to obtain approximately one spectrum per sputtered equivalent nanometer (eq-nm) for the first $10 \mathrm{~nm}$ then one spectrum per 4 eq- $\mathrm{nm}$. The variation of the peak's intensities was reported as a function of the equivalent sputtered depth in $\mathrm{SiO}_{2}$ eq-nm.

AES microscopy was used as a complementary technique to GD-OES and ToF-SIMS, to determine the distribution of the remaining trivalent chromium conversion coating on the $\mathrm{ZnNi}$ alloy in the two types of craters and it was compared the unsputtered conversion coating. To do so, local in-depth chemical profiles were performed in the conversion coating at various locations of the craters. In order to observe the effect of the surface roughness on sputtering, two types of zones were identified using the secondary electron (SEM) images: the hills and the valleys (Fig. 1e). It should be noted that since the ion sputtering of the surface for local composition profiles was in the nanometer range, it had a limited impact on the surface topography. SEM image was therefore used to correct the sample shift during chemical profile acquisitions, ensuring the analysis was performed in the areas of interest.

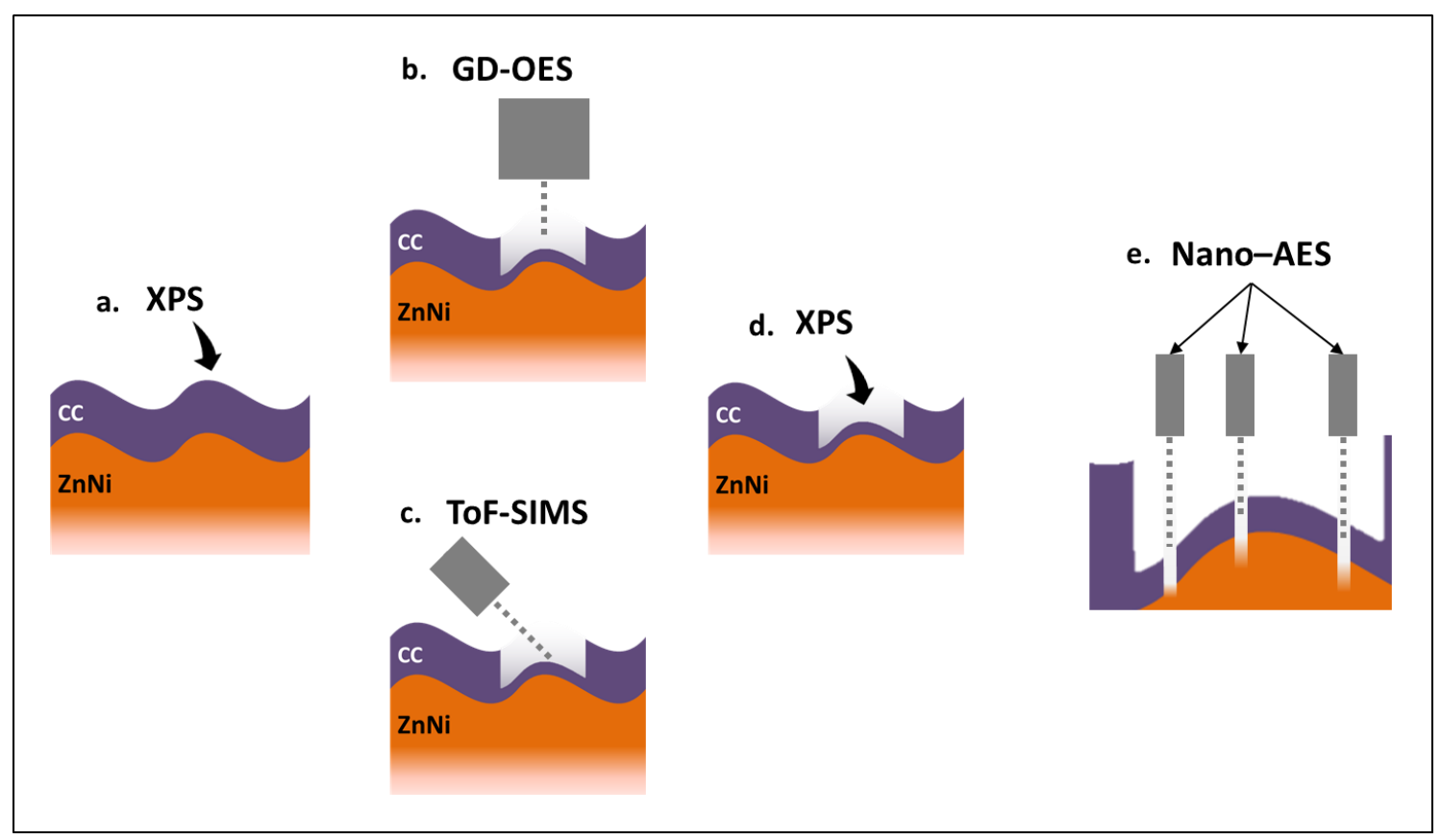

Figure 1: Scheme illustrating the methodological approach used to describe in-depth chemical characterization of thin conversion coatings (CC) on rough substrates (ZnNi): a) XPS surface characterization of unsputtered CC coating, b) GD-OES sputtering at $90^{\circ}$ relative to the surface sample, c) ToF-SIMS sputtering at $45^{\circ}$ relative to the surface sample, d) XPS analysis in the sputtered area prepared by GD-OES or TOF-SIMS, e) Nano-AES localized analysis in the different areas (hills and valleys) of sputtered area prepared by GD-OES or ToF-SIMS.

\section{Results and discussion}

\subsection{Surface composition of $\mathrm{ZnNi}$ alloy with conversion layer}

The XPS results obtained on the model $\mathrm{Zn}(\mathrm{OH})_{2}$ thin film sample and $\mathrm{ZnNi}$ alloy after the conversion treatment in trivalent chromium passivation bath are presented in Fig. 2. Because of the 
superposition of $\mathrm{Zn}$ Auger $\left(\mathrm{Zn} \mathrm{L}_{3} \mathrm{M}_{23} \mathrm{M}_{45}\right)$ peaks in the $\mathrm{Cr} 2 \mathrm{p}$ core level region (Fig. 2f), the preliminary XPS characterization of the model $\mathrm{Zn}(\mathrm{OH})_{2}$ was required. The analysis of model $\mathrm{Zn}(\mathrm{OH})_{2}$ sample allowed the detection and the quantitative analysis of $\mathrm{Zn}$ Auger peaks overlaid with $\mathrm{Cr} 2 \mathrm{p}$ peaks. As a result, the contribution of the $\mathrm{Zn}$ Auger peaks was subtracted from the $\mathrm{Cr} 2 \mathrm{p}$ region and a quantitative analysis of $\mathrm{Cr}$ and $\mathrm{Zn}$ was obtained.

\subsection{1. $\mathrm{Zn}(\mathrm{OH})_{2}$ reference sample}

The survey spectrum recorded on the reference $\mathrm{Zn}(\mathrm{OH})_{2}$ after cleaning (not presented here) indicated only the presence of zinc and oxygen and small carbon contamination.

Fig. 2 a, b, and c show $Z n 2 p, Z n L_{3} M_{45} M_{45}$ (LMM) and $Z_{n} L_{3} M_{23} M_{45}$ Auger signals, respectively. Due to the significant spin-orbit splitting of $Z n 2 p_{3 / 2}$ and $Z n 2 p_{1 / 2}$ ( $\triangle B E$ of around $23 \mathrm{eV}$ ), only $Z n 2 p_{3 / 2}$ was decomposed. The fitting of the $\mathrm{Zn} 2 \mathrm{p}_{3 / 2}$ was done with a single symmetrical peak at $1023.1 \mathrm{eV}$ (Fig. 2a). The details of the peak decomposition are shown in Table 1. However, due to the overlapping of the zinc oxide and zinc metal contributions in the $\mathrm{Zn} 2 \mathrm{p}_{3 / 2}$ peak, the calculation of modified Auger parameter was necessary for the identification of $\mathrm{Zn}$ chemical state $[47,46]$. The modified Auger parameter (using the position of the $\mathrm{Zn} 2 \mathrm{p}_{3 / 2}$ and LMM peaks) was $2009.2 \mathrm{eV}$, which confirmed the presence of zinc hydroxide on the surface $[47,48]$.

The second $\mathrm{ZnL}_{3} \mathrm{M}_{23} \mathrm{M}_{45}$ Auger signal (Fig. 2c) was acquired in order to get information about the peak shape and intensity in order to be able to subtract its contribution from the $\mathrm{Cr} 2 p$ core level peaks occurring in the same range of binding energies (for the conversion coated samples showing the presence of $\mathrm{Cr}$ oxides as described hereafter). In this region, the signal shows two peaks: $\mathrm{L}_{3} \mathrm{M}_{23} \mathrm{M}_{45}\left({ }^{1} \mathrm{P}\right)$ and $\mathrm{L}_{3} \mathrm{M}_{23} \mathrm{M}_{45}\left({ }^{3} \mathrm{P}\right)$, which are labeled as $\mathrm{Zn}$ (II) $A_{1}$ and $\mathrm{Zn}$ (II) $A_{2}$, respectively (Fig. 2c). Then, the area ratio of these peaks $\left(A_{1}\right.$ and $\left.A_{2}\right)$ versus $Z n L M M$ peak was 0.168 and 0.270 , respectively. The relative position of the two $\mathrm{Zn}$ Auger peaks $\left(\mathrm{Zn} \mathrm{L}_{3} \mathrm{M}_{23} \mathrm{M}_{45}\right)$ was measured: $\triangle B E\left(\mathrm{Zn} A_{2}\right.$

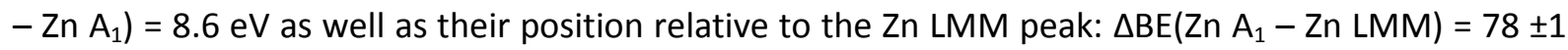
$\mathrm{eV}$. These values will be used for quantitative chemical analysis (chromium and zinc species) for the conversion coated $\mathrm{ZnNi}$ alloys.

\subsubsection{Surface atomic composition of the conversion coating}

The survey spectrum recorded for chromium passivated $\mathrm{ZnNi}$ (not presented here) indicated the presence of carbon, oxygen, zinc and chromium as main components and traces of sodium, chlorine, calcium and aluminium on the surface. Nickel was not detected on the survey and on the highresolution spectrum ( $\mathrm{Ni} 2 \mathrm{p}$ region), indicating either a very small amount or the absence of nickel in the conversion coating.

Fig. $2 \mathbf{d}$, $\mathbf{e}$ and $\mathbf{f}$ show XPS high resolution spectra of $\mathrm{Zn} 2 \mathrm{p}, \mathrm{Zn}$ LMM and $\mathrm{Cr} 2 \mathrm{p}$ together with $\mathrm{Zn}$ $\mathrm{L}_{3} \mathrm{M}_{23} \mathrm{M}_{45}\left({ }^{1} \mathrm{P}\right)$ and $\mathrm{L}_{3} \mathrm{M}_{23} \mathrm{M}_{45}\left({ }^{3} \mathrm{P}\right)$ peaks of chromium passivated $\mathrm{ZnNi}$. Peak assignment and fitting parameters are reported in Table $\mathbf{2}$.

The $\mathrm{Zn} 2 \mathrm{p}_{3 / 2}$ peak was fitted with a single peak at $1023.7 \mathrm{eV}$. The value of the modified Auger parameter of 2009.4 eV confirmed the presence of $\mathrm{Zn}(\mathrm{OH})_{2}$ on the top surface layer [48]. Thus, it was possible to use the fitting parameters extracted from the reference $\mathrm{Zn}(\mathrm{OH})_{2}$ sample showing also the presence of $\mathrm{Zn}(\mathrm{OH})_{2}$ on the extreme surface as described above. The measured binding energies and the calculated $\mathrm{Zn} L M M$ to $Z n A_{1}$ and $Z n A_{2}$ peaks area ratio was used to identify the $\mathrm{Zn}$ Auger peaks in the $\mathrm{Cr} 2 \mathrm{p}$ region (Fig. 2f). The position of the $\mathrm{Cr} 2 \mathrm{p}_{3 / 2}$ peak at $577.2 \mathrm{eV}$ indicates the presence of $\mathrm{Cr}$ (III) species in the conversion coating $[49,50]$. According to quantitative analysis on the $\mathrm{Cr} 2 \mathrm{p}$ and $\mathrm{Zn} 2 \mathrm{p}_{3 / 2}$ 
peaks, the passivated $\mathrm{ZnNi}$ alloy top surface is composed of zinc hydroxides and trivalent chromium species with an atomic $\mathrm{Zn} / \mathrm{Cr}$ ratio of 1.6 .

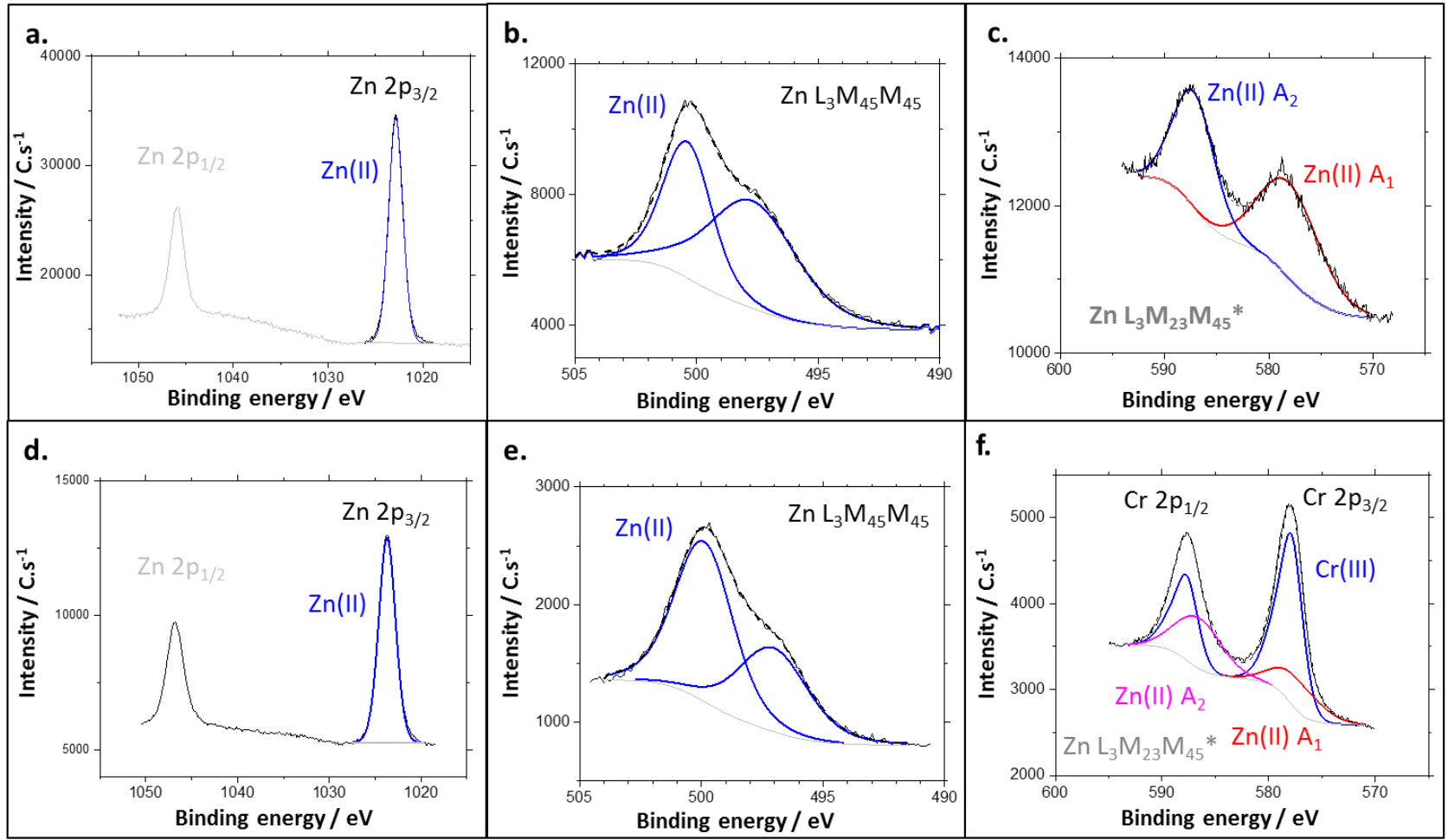

Figure 2: High resolution XPS spectra for the reference $\mathrm{Zn}(\mathrm{OH})_{2}$ sample: (a) $\mathrm{Zn} 2 p$, (b) $\mathrm{Zn} L M M$ Auger $\left(\mathrm{Zn} \mathrm{L}_{3} \mathrm{M}_{45} \mathrm{M}_{45}\right)$ and (c) $\mathrm{Zn}$

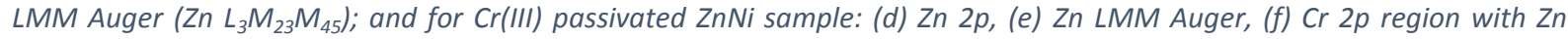
Auger peaks $\left(Z n L_{3} M_{23} M_{45}\right)$.

Table 1: Peak assignment and fitting parameters used for the decomposition of XPS core level spectra of model $\mathrm{Zn}(\mathrm{OH})_{2}$ reference sample presented in Fig. 1. $a, b$ and $c$.

Peak
A : $\mathrm{Zn} \mathrm{L}{ }_{3} \mathrm{M}_{45} \mathrm{M}_{45}$
$B: \mathrm{Zn} \mathrm{L}{ }_{3} \mathrm{M}_{23} \mathrm{M}_{45} \mathrm{Zn}$ (II) $\mathrm{A}_{2}$
$C: \mathrm{Zn} \mathrm{L}{ }_{3} \mathrm{M}_{23} \mathrm{M}_{45} \mathrm{Zn}$ (II) $\mathrm{A}_{1}$
$\mathrm{D}: \mathrm{Zn} 2 \mathrm{p}_{3 / 2}$

Peak BE (eV)

500.5

586.9

578.3

1023.1

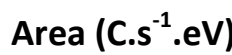

FWHM (eV)

$74751 \quad \varnothing$

20252

3.4

12531

3.4

19143

2.0

Table 2: Peak assignment and fitting parameters used for the decomposition of XPS core level spectra of trivalent conversion coating on ZnNi substrate sample presented in Fig. 1. d, e and f.

\section{Peak}
A : $\mathrm{Zn} \mathrm{L}{ }_{3} \mathrm{M}_{45} \mathrm{M}_{45}$
B : $\mathrm{Cr} 2 \mathrm{p}_{3 / 2}$
C : $\operatorname{Cr} 2 \mathrm{p}_{1 / 2}$
$D: Z n L_{3} M_{23} M_{45} Z n(I I) A_{1}$

\section{Peak BE (eV)}

500.9

577.2

$587.1(B+9.8( \pm 0.2))$

$584.3(A+77.8( \pm 0.2))$
Area (C.s-1.eV)

FWHM (eV)

2833

6358

3.0

$718(B * 0.5)$

$3.0(B * 1)$

$476(A * 0.168)$ 


\subsubsection{Chemical composition of the conversion coating by ToF-SIMS and GD-OES depth profiles}

To detect the composition in bulk of the conversion coating and the conversion coating / $\mathrm{ZnNi}$ alloy interface, depth profiling was performed by means of ToF-SIMS and GD-OES techniques. In these profiles, the variation of the ion or element intensity with sputtering time reflects the variation of the in-depth concentration of the species as shown in Fig. 3. As in XPS, in GD-OES and ToF-SIMS profiles nickel does not appear at the beginning of sputtering in the conversion coating. Therefore, the metal-oxide interface zone was defined from the increase of the intensity of the Ni signal. ToFSIMS ion depth profiles performed on the sample with trivalent chromium conversion coating are presented in Fig. 3a. The ions characteristic of the coated sample $\mathrm{CrO}_{2}^{-}(83.9285 \mathrm{u}), \mathrm{ZnO}^{-}(79.9252 \mathrm{u})$ and $\mathrm{Ni}_{2}{ }^{-}(57.2516 \mathrm{u})$ correspond to the oxidized chromium typical for chromium-based conversion coatings [19,23,51, 52,53], zinc oxide and nickel as the $\mathrm{ZnNi}$ substrate species [22], respectively. The intensity of the ions varies as a function of sputtering time. The intensity is presented in the logarithmic scale to enhance the low intensity signals. Three regions can be distinguished here as a function of sputtering depth:

- the conversion coating region (up to about $50 \mathrm{~s}$ of sputtering) with a high and stable intensity of $\mathrm{CrO}_{2}{ }^{-}, \mathrm{ZnO}^{-}$signals, and no Ni signal,

- the metal-oxide interface region (from $50 \mathrm{~s}$ to about $130 \mathrm{~s}$ ) with $\mathrm{CrO}_{2}{ }^{-}$decrease and $\mathrm{ZnO}^{-}$and $\mathrm{Ni}_{2}{ }^{-}$intensity increase,

- the substrate region (from about $\sim 130 \pm 15 \mathrm{~s}$ ) with a stable intensity of $\mathrm{ZnO}^{-}$and $\mathrm{Ni}_{2}{ }^{-}$signals.

The presence of chromium and zinc oxidized species in the conversion coating layer is consistent with the XPS results presented above. The gradual decrease or increase of ion signals at the metaloxide interface is attributed to the significant surface roughness of the electrodeposited $\mathrm{ZnNi}$ [25]. The surface roughness will be also discussed hereafter.

The in-depth homogeneity of the conversion coating can be estimated from the ratio of the $\mathrm{ZnO}^{-}$ to $\mathrm{CrO}_{2}{ }^{-}$shown in Fig. $3 \mathbf{b}$. The $\mathrm{ZnO}^{-}$to $\mathrm{CrO}_{2}^{-}$ratio of about 0.6 is stable within the sputtering time corresponding to the conversion coating (from 10 to $40 \mathrm{~s}$ ), whereas on the top surface (up to $10 \mathrm{~s}$ of sputtering), it reaches 1.5. This indicates that the conversion coating has a homogeneous in-depth chemical composition with a segregation of zinc species on the extreme surface. The lower intensity of $\mathrm{CrO}_{2}^{-}$on the top surface can be also related to surface enrichment in the hydroxides and contaminants.

The same conversion coated sample was also characterized by GD-OES. The GD-OES elemental depth profiles of carbon, oxygen, chromium, zinc, nickel and iron were performed at high sputtering rate as presented in Fig. 3c. Similarly, to ToF-SIMS ion depth profiles, different regions can be distinguished in GD-OES elemental depth profiles. The first three regions are the same as the regions observed by ToF-SIMS ion depth profiles, and the last (the steel substrate) region was not attained by ToF-SIMS due to much lower sputtering rate. The GD-OES four regions, which can be distinguished in Fig. 3c are: 
- the conversion coating region (from 0.3 to $1.3 \mathrm{~s}$ ) with high and stable intensity of chromium, zinc and oxygen signals, where no nickel is detected,

- the metal-oxide interface region (from $1.3 \mathrm{~s}$ to about $5 \mathrm{~s}$ ) with $\mathrm{Cr}$ and $\mathrm{O}$ intensity decrease and $\mathrm{Zn}$ and $\mathrm{Ni}$ intensity increase,

- the $\mathrm{ZnNi}$ region (from $5 \mathrm{~s}$ to about $100 \mathrm{~s}$ ) with a stable intensity of $\mathrm{Zn}$ and Ni signals,

- the steel substrate region (from about $100 \mathrm{~s}$ ) where the $\mathrm{Fe}$ and $\mathrm{Cr}$ signal intensities increase.

As for the ion depth profiles obtained by ToF-SIMS, the gradual decrease and increase of the chromium and nickel intensities, respectively, at the metal-oxide interface region are the result of the rough $\mathrm{ZnNi}$ surface. The roughness in the interfacial region can be also enhanced during the sample immersion in the conversion bath. In the first tenth of second of sputtering, in the top surface region, the intensity of the zinc signal is higher than deeper in the conversion coating, indicating a segregation of $\mathrm{Zn}$-containing species on the extreme surface of the conversion coating. The conversion coating enrichment in $\mathrm{Zn}$ species was also demonstrated by the higher ToF-SIMS $\mathrm{ZnO}^{-}$ $/ \mathrm{CrO}_{2}^{-}$ratio at the beginning of sputtering time (Fig. 3.b). According to the intensity of the carbon signal in the first tenth seconds of sputtering, the presence of a surface contamination is also confirmed.

To better observe the chemical distribution of the thin conversion coating on ZnNi substrate, the low energy Ar plasma sputtering (as described in the experimental part) was also applied and the elemental profiles are shown in Fig. 3d. the application of low energy Ar plasma sputtering was also necessary in order to obtain well resolved elemental profiles and better define the time of sputtering to reach the conversion coating/ZnNi interface. The analysis was necessary for further preparation of a crater defect, which will be discussed below.

To sum-up, ToF-SIMS and GD-OES analysis confirmed that the surface of passivated ZnNi alloy is mainly composed of zinc hydroxides segregated on the top surface and chromium oxide species. Nickel was not detected in the conversion coating. It was also demonstrated that some C-like contaminants are essentially present at the extreme surface of the conversion coating. GD-OES showed also that these $\mathrm{C}$-like contaminations can penetrate inside the conversion coating, which can be explained by the coating porosity and presence of some cracks leading to the contamination during exposure to the ambient air [16]. 


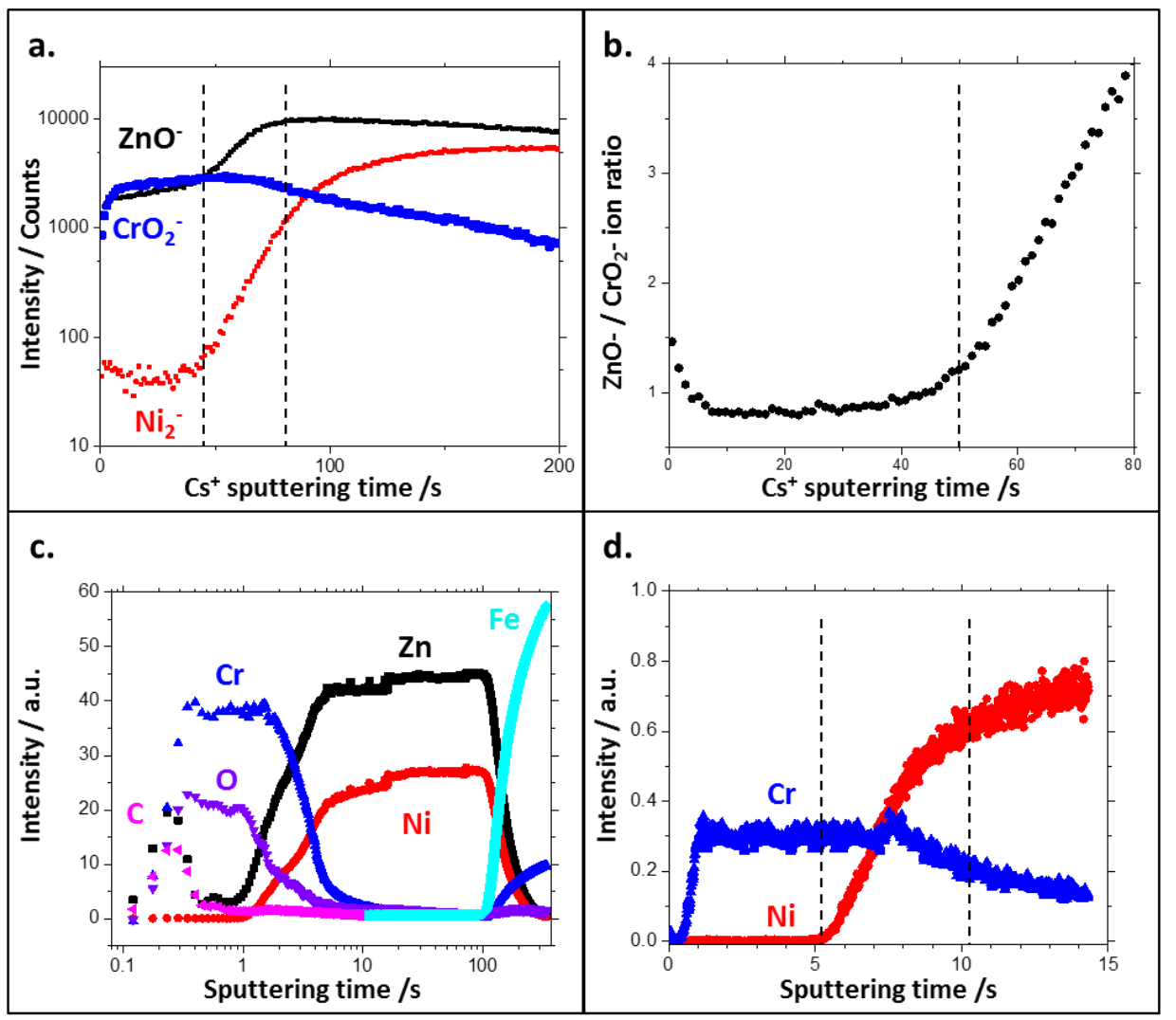

Figure 3: (a) ToF-SIMS secondary ion depth profiles ( $\mathrm{ZnO}^{-} \mathrm{CrO}^{-}$and $\mathrm{Ni}_{2}{ }^{-}$) on passivated $\mathrm{ZnNi}$ surface, (b) ToF-SIMS $\mathrm{ZnO}^{-}$to $\mathrm{CrO}_{2}{ }^{-}$ions ratio profile during the $80 \mathrm{~s}$ of sputtering corresponding to the thickness of passivation layer. GD-OES elemental depth profiles ( $\mathrm{Cr}, \mathrm{O}, \mathrm{C}, \mathrm{Ni}, \mathrm{Zn}, \mathrm{Fe}$ ) on passivated ZnNi alloy: (c) high energy argon plasma, (d) low power argon plasma.

\subsection{Chemical characterization of the interface conversion coating / substrate alloy}

\subsubsection{Crater generation}

As aforementioned, the chromium and nickel elemental in-depth profiles performed with low sputtering rate (using specific plasma conditions of GD-OES $650 \mathrm{~Pa}, 8 \mathrm{~W}$ ) presented in Fig. 3d were used to precisely define the sputtered depth. In these sputtering conditions, the conversion coating is sputtered during about $5 \mathrm{~s}$ (Fig. 3d). Thus, considering the time of sputtering necessary to reach a near-interface region, the crater in the conversion coating was performed at $80 \%$ of the depth of the interface: $4 \mathrm{~s}$ of sputtering. A schematic representation of this model defect and the observation by optical microscope of the surface in the vicinity of the defect are presented in Fig. 4a and Fig. 4c. The sputtered area of about $2 \mathrm{~mm}$, consistent with the use of $2 \mathrm{~mm}$-diameter anode, is easily distinguished in the optical microscopy image where the sputtered region shows a grey color while the undamaged conversion coating shows a brown gold color. The slightly darker area on the border of circle-shape sputtered area is attributed to a redeposition of eroded species in the argon plasma.

Similar approach was used in the case of the ToF-SIMS craters generation. The time necessary to reach the near-interface region was evaluated based on the ion depths profiles $\left(\mathrm{Ni}_{2}{ }^{-}\right.$and $\left.\mathrm{CrO}_{2}{ }^{-}\right)$. The 
conversion coating layer was sputtered up to $80 \%$ of the interfacial depth. 49 defects (a square grid of $7 \times 7$ defects with size and space between each as presented in Fig. 4.b) constituting a grid-pattern defect of about $800 \times 800 \mu \mathrm{m}^{2}$, were performed in the conversion coating. The image of this gridpattern defect is shown in Fig. 4d. As for the $2 \mathrm{~mm}$ in diameter defect generated by GD-OES, the sputtered areas are easy to be distinguished from the undamaged areas because of the different color. No darker area attributed to the re-deposition of species could be found. Although each of the 49 defects can be detected on the optical microscopy image, their size and shape are not consistent with a grid of $30 \mu \mathrm{m}$ size squares spaced by $100 \mu \mathrm{m}$ distance between the centers of the squares. The difference is attributed to the sprawl of the focused oxygen beam of the ToF-SIMS and/or the rough surface on which the sputtering was performed. According to the observation, the obtained dispersion of defects is more consistent with a grid of defects with $\sim 70 \mu \mathrm{m}$ in diameter spaced by $\sim 60$ $\mu \mathrm{m}$.

\subsubsection{Surface morphology and distribution of the conversion coating in the sputtered areas}

A topographic analysis in the defects prepared by GD-OES and ToF-SIMS sputtering was performed. The roughness of the electrodeposited ZnNi alloy in both types of defect as well as far away from the defects were evaluated from these topographic mappings. No significant differences were observed between the values of the arithmetical mean deviation roughness $R_{a}(\sim 5 \mu \mathrm{m})$ between the three types of surfaces. These results were predictable since the roughness of the $\mathrm{ZnNi}$ is in the range of the dozens of micrometers while the thickness of the sputtered conversion coating is of three orders of magnitude below, i.e. in the dozens of nanometer range.

In addition to topographic images, high magnification optical images were obtained by 3Dcomposition of multiple images obtained with different depths as described in section 2 . The Fig. 4e. and $\mathbf{f}$ present a comparison of sputtered (left) and non-sputtered (right) areas for both samples. Apart from the difference in the surface color of these two types of areas, the surface topography appears unchanged after the sputtering. The micro-roughness and the cauliflower-shape remain typical of electrodeposited $\mathrm{ZnNi}$ (which is caused by a competition between nucleation and grain growth) [54].

In the defect generated by GD-OES (Fig. 4e on the left), the color of the surface is homogeneous and grey, while the color of the unsputtered surface is goldish (Fig. 4e on the right). On the contrary, in the defect generated by ToF-SIMS (Fig. 4f on the top left), the surface color is more heterogeneous. The hills (i.e. the highest zones of the surface) show the same grey color as in the GD-OES crater; however, around the valleys (i.e. the deepest areas), the surface exhibits a goldish color. The presence of this "conversion coating color-like" in the defect could indicate that some undamaged or slightly sputtered conversion coating remained in the valleys of the surface after ToFSIMS sputtering. This could be explained by the low incidence angle ToF-SIMS ion gun and therefore some shadowing effect. The GD-OES generated defects does not seem to be influenced by sputtering, probably because the acceleration of the argon plasma is normal to the surface. 

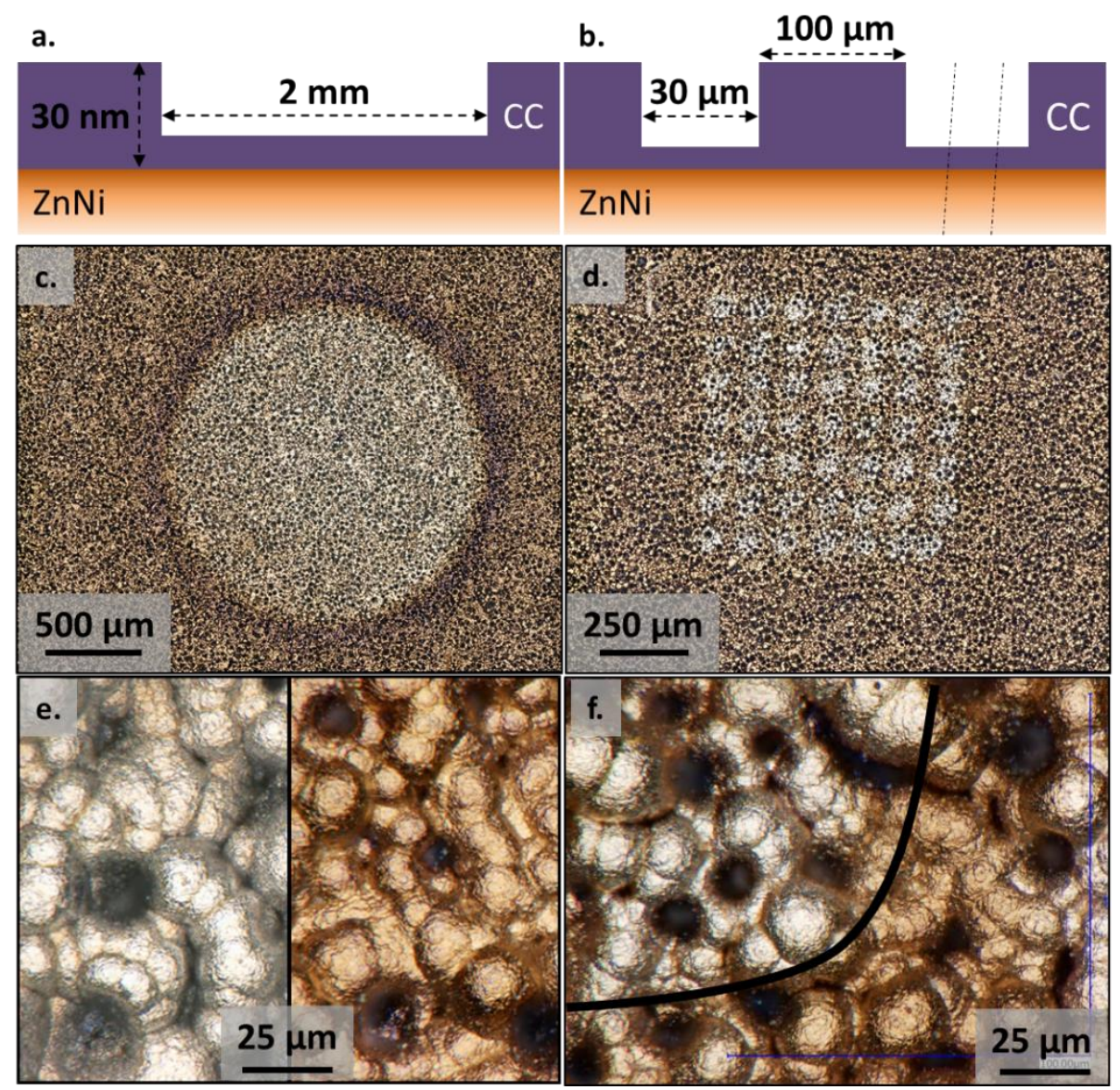

Figure 4: Schematic representation of the generated model defect: (a) $2 \mathrm{~mm}$ anode with GD-OES, (b) $30 \mu \mathrm{m}$ oxygen ion source with ToF-SIMS; and optical micrographs of the defects by Keyence high resolution 3D microscope: (c) $2 \mathrm{~mm} c r a t e r$ produced by GD-OES, (d) Grid of 49 defects produced by ToF-SIMS. High magnification optical microscopy comparison of sputtered and unsputtered regions (e) of GD-OES $2 \mathrm{~mm}$ defect, (f) of ToF-SIMS defect.

\subsubsection{Chemical composition near the conversion coating/substrate interface}

In addition to the morphological study and the analysis of the distribution of the conversion coating in the sputtered area, the chemical composition of the remaining conversion coating after ToF-SIMS and GD-OES sputtering was analyzed by XPS.

\section{GD-OES crater}

Fig. 5 a, $\mathbf{b}$ and $\mathbf{c}$ show XPS high resolution spectra of $\mathrm{Zn} 2 \mathrm{p}, \mathrm{Zn}$ LMM and $\mathrm{Cr} 2 \mathrm{p}$ together with $\mathrm{Zn}$ $\mathrm{L}_{3} \mathrm{M}_{23} \mathrm{M}_{45}\left({ }^{1} \mathrm{P}\right)$ and $\mathrm{L}_{3} \mathrm{M}_{23} \mathrm{M}_{45}\left({ }^{3} \mathrm{P}\right)$ peaks in the $2 \mathrm{~mm}$ in diameter model defect generated by GD-OES.

The $\mathrm{Zn} 2 \mathrm{p}_{3 / 2}$ peak (Fig. 5a) was fitted with two symmetrical peaks at $1023.4 \mathrm{eV}$ and $1021.6 \mathrm{eV}$, which can be attributed to the $\mathrm{Zn}(\mathrm{II})$ in the conversion coating and the metallic $\mathrm{Zn}$, respectively. The Zn LMM peak (Fig. 5b) was fitted according to the fitting performed on the undamaged conversion coating presented above (Fig. 2e). It shows a third peak at lower binding energy of $494.9 \mathrm{eV}$, which can be attributed to $\mathrm{Zn}$ metal. The presence of metallic $\mathrm{Zn}$ corresponding to the $\mathrm{ZnNi}$ alloy substrate indicates that the thickness of the remaining conversion coating after sputtering is less than ten nanometers [55].

The modified Auger parameters for the two zinc species were calculated for the high and low energy $\mathrm{Zn} 2 \mathrm{p}(\mathrm{BE}=1023.4 \mathrm{eV}$ and $\mathrm{BE}=1021.6 \mathrm{eV})$ peaks to $\mathrm{Zn} \mathrm{LMM}(\mathrm{BE}=500.6 \mathrm{eV}$ and $\mathrm{BE}=495.9 \mathrm{eV})$. 
The two Auger parameters equal $2009.5 \mathrm{eV}$ and $2013.4 \mathrm{eV}$, respectively. According to the literature, the value of 2009.5 indicates the presence of zinc hydroxides, although this value is slightly higher compared to the $\mathrm{Zn}(\mathrm{OH})_{2}$ reference $(2009.2 \mathrm{eV})$ and might show the presence of hydrozincite [48]. The formation of hydrozincite on the top surface of the sample could be explained by the formation of carbonate contamination of the zinc hydroxide on the surface as confirmed by the analysis of the C 1s peaks (not shown here). The value of $2013.4 \mathrm{eV}$ confirms the presence of metallic zinc [48].

Assuming that the possible presence of hydrozincite does not influence significantly the position of the zinc Auger peaks, the parameters extracted from the reference $\mathrm{Zn}(\mathrm{OH})_{2}$ sample showing also the presence of $\mathrm{Zn}(\mathrm{OH})_{2}$ on the extreme surface were used to subtract the zinc Auger contribution in the $\mathrm{Cr} 2 p$ region as described above (Fig. 2f). Here (Fig. 5c), two contributions attributed to the zinc hydroxide (Zn (II) A1 and Zn(II) A2 peaks) and two to the metallic zinc ( $\mathrm{Zn}(\mathrm{m}) \mathrm{A} 1$ and $\mathrm{Zn}(\mathrm{m}) \mathrm{A2}$ ) were considered. As for the zinc hydroxide, the same methodology was used to calculate the $\mathrm{BE}$ and the areas of the two zinc metallic peaks, using the Zn LMM peak attributed to the metallic Zn (BE $=494.9$ $\mathrm{eV})$. The decomposition of the spectra is presented in Fig. $\mathbf{5 c}$.

The other peaks in the area of $\mathrm{Cr} 2 \mathrm{p}_{3 / 2}$ region are the asymmetrical peak at $577.3 \mathrm{eV}$, attributed to $\mathrm{Cr}$ (III) species as described above (Fig. 2c) and a higher binding energy peak at $580.5 \mathrm{eV}(+3.2 \mathrm{eV}$ ), which corresponds to the traces of $\mathrm{Cr}(\mathrm{VI})$ species, which could be formed occasionally at the interface in $\mathrm{Cr}(\mathrm{III})$ based conversion coating [45]. The quantitative analysis of the $\mathrm{Cr} 2 p$ (considering all $\mathrm{Cr}$ species) and $\mathrm{Zn} 2 \mathrm{p}_{3 / 2}$ peak corresponding to the oxidized zinc species shows that the composition of the remaining conversion layer is similar to the top surface where zinc hydroxides to Cr-species atomic ratio is about 1.8. These results are in agreement with the ToF-SIMS ion profiles showing a stable intensity of $\mathrm{Zn}$ and $\mathrm{Cr}$-corresponding signals all over the conversion layer thickness as discussed above (Fig. $\mathbf{3}$ a and $\mathbf{b}$ ).

\section{ToF-SIMS crater}

Similar XPS analysis was performed on the sample with the ToF-SIMS defect. Fig. $\mathbf{5} \mathbf{d}, \mathbf{e}, \mathbf{f}$ show high resolution XPS spectra of $\mathrm{Zn} 2 \mathrm{p}, \mathrm{Zn} L \mathrm{LMM}$ and $\mathrm{Cr} 2 \mathrm{p}$ together with $\mathrm{Zn} \mathrm{L}_{3} \mathrm{M}_{23} \mathrm{M}_{45}\left({ }^{1} \mathrm{P}\right)$ and $\mathrm{L}_{3} \mathrm{M}_{23} \mathrm{M}_{45}\left({ }^{3} \mathrm{P}\right)$ peaks in the area of craters generated by ToF-SIMS.

Since the XPS spectra were performed in identical conditions in both GD-OES and ToF-SIMS sputtered area, the signal intensity in the case of the ToF-SIMS defect is expected to be lower because of the heterogeneity of the surface chemistry. Indeed, the analyzed area consists of both sputtered and non-sputtered areas. The same fitting parameters used for the XPS results obtained in the GD-OES-made defect were applied for the decomposition of XPS spectra obtained in the ToFSIMS defects.

The $\mathrm{Zn} 2 \mathrm{p}_{3 / 2}$ peak (Fig. $\mathbf{5 d}$ ) is similar to $\mathrm{Zn} 2 \mathrm{p}_{3 / 2}$ peak obtained for the GD-OES-made defect (Fig. 5a) and two peaks at $1023.7 \mathrm{eV}$ and $1021.8 \mathrm{eV}$ attributed to the $\mathrm{Zn}(\mathrm{II})$ in the conversion coating and the metallic $\mathrm{Zn}(0)$ respectively, can be observed. The presence of metallic $\mathrm{Zn}$ can be confirmed by the Zn LMM Auger signal (Fig. 5e) where a lower binding energy peak (at $495.0 \mathrm{eV}$ ) corresponding to the metallic $\mathrm{Zn}$ is observed. The $\mathrm{Zn}$ LMM shows the same characteristic peaks as described here above for GD-OES-made defect. The values of the modified Auger parameters: $2009.4 \mathrm{eV}$ for the high $\mathrm{Zn} 2 \mathrm{p}$ binding energy peak and $2013.4 \mathrm{eV}$ for the low energy $\mathrm{Zn} 2 \mathrm{p}$ are consistent with the presence of zinc hydroxides or hydrozincite in the conversion coating and metallic zinc underneath.

In the case of the decomposition of the XPS in the $\mathrm{Cr} 2 \mathrm{p}$ core level (Fig. 5f), the methodology described previously was used. The peak at $577.5 \mathrm{eV}$ was attributed to the presence of $\mathrm{Cr}$ (III) species and here the presence of $\mathrm{Cr}(\mathrm{VI})$ species was not observed. Similar to GD-OES generated crater, the 
ratio between zinc hydroxides and $\mathrm{Cr}$-species is about 1.8 in the remaining layer, very close to the composition of the top surface.

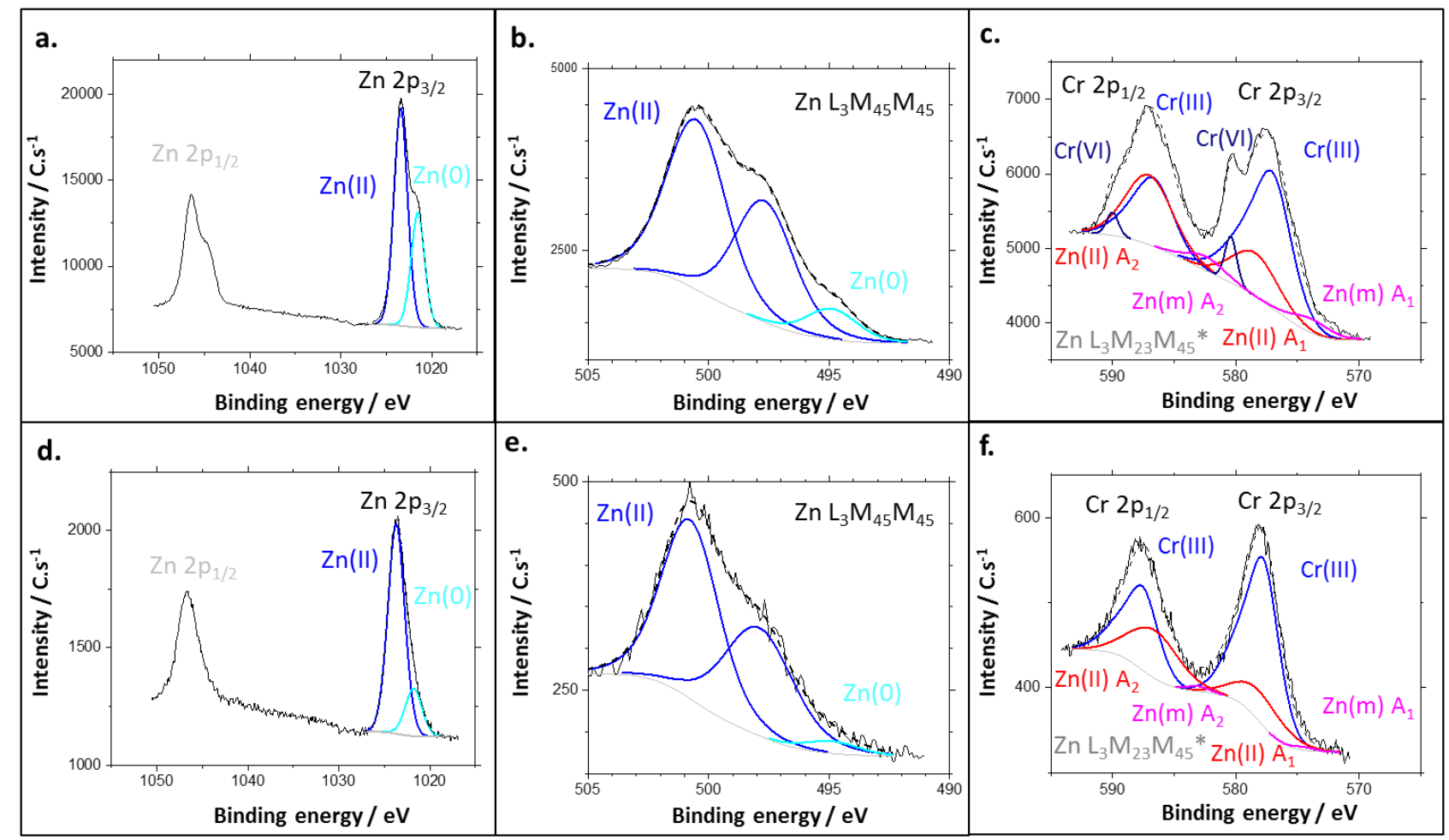

Figure 5: High resolution XPS spectra performed in the middle of the GD-OES crater: (a) Zn 2p, (b) $Z n L_{3} M_{45} M_{45} A$ Ager, (c) Cr $2 p$ region with $Z n$ Auger peaks ( $\left.Z n L_{3} M_{23} M_{45}\right)$; and in the middle of the grid of 49 defects produced by ToF-SIMS: (d) $Z n$ 2p, (e) $\mathrm{Zn}$ LMM Auger, (f) $\mathrm{Cr} 2 p$ region with $\mathrm{Zn}$ Auger peaks ( $\left.\mathrm{Zn} \mathrm{L}_{3} \mathrm{M}_{23} \mathrm{M}_{45}\right)$.

\subsubsection{Local chemical composition in sputtered area by nano Auger}

Scanning electron microscopy (SEM) images of the samples prepared by both, GD-OES (Fig. 6a) and ToF-SIMS (Fig. 7b) sputtering, clearly show the sputtered zones. Lighter sputtered and darker non-sputtered areas related to the different chemical contrast between the heavier (metallic $\mathrm{ZnNi}$ substrate) and lighter elements (carbon and oxygen present in the conversion coating), respectively.

Fig. 6a shows the SEM images of the crater obtained by GD-OES. The surface morphology observed by SEM corroborates with the optical microscopy results (Fig. 4c). The crater measures approximatively $1.8 \mathrm{~mm}$ in diameter. Three different areas are detailed: one near the center of the crater, one close to the border of the crater, and one outside the crater to serve as a reference. The high-resolution SEM image of the area in the center of the crater is presented in Fig. $\mathbf{6 b}$. As already observed by the optical microscopy image (Fig. 4e) the SEM reveals also the same roughness and the cauliflower-type topography. On this figure, three valley-type, and three hill-type features of the surface are highlighted by black and white circles, respectively. The same types of zones (hills and valleys) were identified on the three different areas (in the center, on the border and outside the crater). Local Auger depth profiles were performed on these twelve (6 valleys and 6 hills) specific areas. 
Fig. $\mathbf{6 c}$ shows the nickel and chromium Auger in-depth profiles performed outside the sputtered crater. Only the first 16 eq. $\mathrm{nm}$ are presented to show the depth of the conversion coating in details. The results agree with the GD-OES and ToF-SIMS profiles, showing a layer containing chromium and depleted in nickel deposited on a nickel containing substrate. The metal-oxide interface, i.e. the beginning of the Ni signal increase, is placed at 7 eq. $\mathrm{nm}$ in depth.

Fig. $6 \mathrm{~d}$ and e show the local Auger depth profiles on the valley and the hill-type areas, respectively. It can be noticed for both profiles that the thickness of the remaining conversion coating is much thinner than outside the crater (Fig. 6c). However, the composition in nickel is around 0 at. $\%$ on the extreme surface (at 0 eq. $\mathrm{nm}$ in depth). In agreement with the depth profiles presented above (Fig. 3), it can be concluded that the ZnNi alloy was not reached by the sputtering of the crater. These results confirm the hypothesis used for XPS analysis performed in the crater and fits the schematic description of the surface (Fig. 4a).

Moreover, both profiles corresponding to the valleys (Fig. 6d) and the hills (Fig. 6e), show the same thickness (about 1 eq. $\mathrm{nm}$ ) of the remaining conversion coating. This indicates that the sputtering by low energy argon plasma with the GD-OES technique is homogeneous on the surface and does not suffer from the roughness of the sample. This result is in agreement with the optical microscopy observation showing a homogeneous color of the sputtered crater by GD-OES (Fig. $4 \mathbf{e}$ on the left).
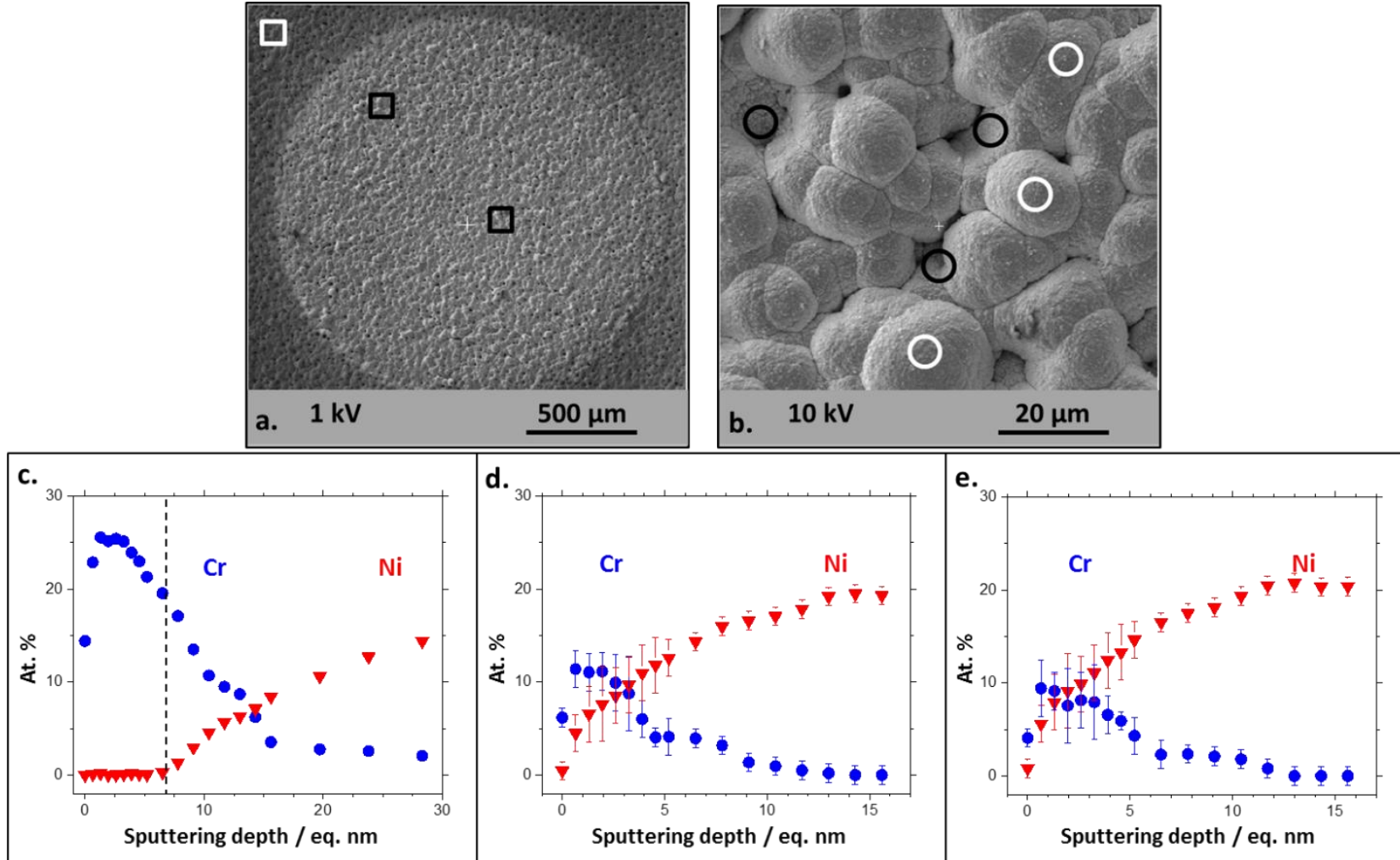

Figure 6: SEM images and Nano Auger elemental profiles in the vicinity of the $2 \mathrm{~mm}$ diameter sputtered area generated by GD-OES. (a) General view showing sputtered and not-sputtered zones, (b) magnification showing an example of the zone selected for AES profiling inside the defect (valley-type zones are shown with black circles while hill-type are shown by white circles). (c) Example of in-depth chemical profiling of chromium and nickel on intact non-sputtered surface, (d) Example of indepth chemical profiling of chromium and nickel in the valley-type zones inside the crater, (e) Example of in-depth chemical profiling of chromium and nickel on the hill-type zones of the crater.

In order to compare the sputtering between the two techniques, a similar analysis was performed in the area of the crater obtained by ToF-SIMS. Fig. 7a. shows the SEM image with two 
different areas one near the center and one near the border of the grid-pattern defect crater. The higher resolution SEM image of the area near the center is presented in Fig. 7b. Here also three valley-type and three hill-type zones were defined and marked with black and white circles, respectively. The same types of zones were considered in the second area (near the border of the crater) of the sample.

Fig. 7c. and Fig. 7d show the local Auger depth profiles on the valley-type and the hill-type areas respectively. As for the GD-OES made crater, the absence of nickel on the top surface (at 0 eq. $\mathrm{nm}$ depth) indicates that the $\mathrm{ZnNi}$ substrate was not exposed by the ToF-SIMS sputtering. However, the comparison between the depth profile in the valley-type (Fig. 7c) and the one in the hill-type (Fig. 7d) areas, the remaining thickness of conversion coating in the valley-type areas is much more important: about 3 eq. $\mathrm{nm}$ versus less than 1 eq. $\mathrm{nm}$. These results clearly indicate that the ToF-SIMS sputtering is more efficient on the hill-type than on the valley-type areas of the surfaces, thus that the influence of the micrometric roughness is important (shadowing effect). This result also confirms our findings by 3D optical microscopy (Fig. 4d) showing a heterogeneous distribution of conversion coating in the craters obtained by ToF-SIMS.

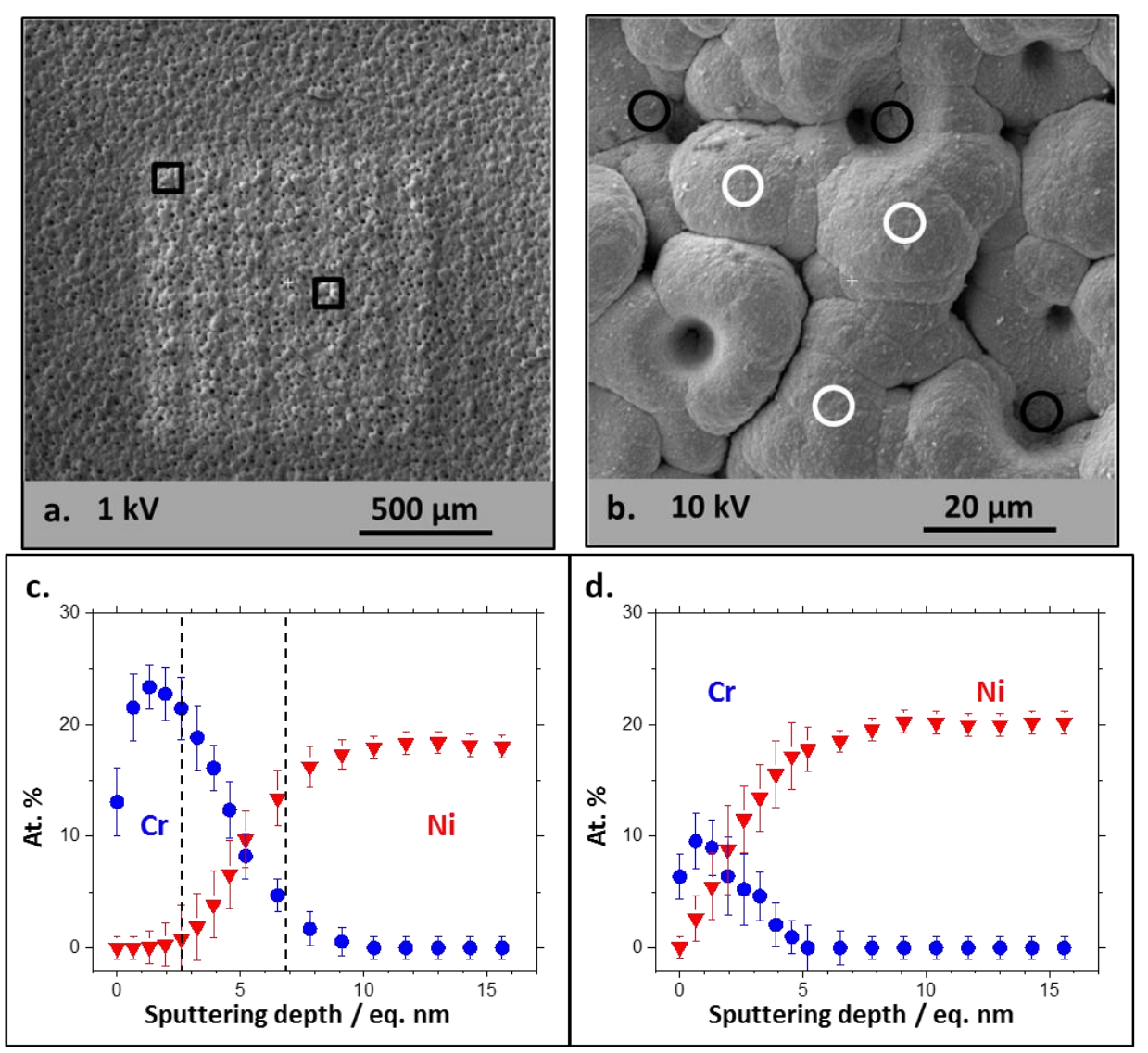

Figure 7: SEM images and Nano Auger elemental profiles in the vicinity of the sputtered area generated by ToF-SIMS. (a) General view showing sputtered and non-sputtered zones, (b) magnification showing an example of the zone selected for AES profiling inside the defect (valley-type zones are shown with black circles while hill-type are shown by white circles). (c) Example of in-depth chemical profiling of chromium and nickel in the valley-type zones inside the crater, (d) Example of indepth chemical profiling of chromium and nickel on the hill-type zones of the crater.

\subsection{Discussion: feasibility of thin layers characterization on rough substrates}


In this work, the attempt to combine different sputtering and surface characterization techniques to explore the in-depth evolution of chemical composition of thin conversion coatings on rough substrates was used. GD-OES and ToF-SIMS were used to reveal the inner part on the thin oxide layer so that high resolution XPS acquisition could be performed in the depth of the conversion coating. Auger electron microscopy, which seems to be the less sensitive to the sample surface topography, especially when equipped with co-axial cylindrical mirror analyzer [36], and extensively used for local surface characterization and in-depth chemical profiles of oxide layers $[40,56]$ was proposed to verify the lateral distribution of the remaining conversion coating after surface sputtering by GD-OES and ToF-SIMS.

Our work highlighted that the crater generation by ToF-SIMS on rough surfaces can result in a heterogeneous sputtering, especially a lack of sputtering in the "deep valleys" of the surface. Although various factors can lead to this effect, like local incident ion beam variation due to the surface roughness, shadowing effect seems more consistent $[57,58]$.

As the GD-OES permitted to perform homogeneous sputtering of the conversion coatings on rough surfaces in the proposed conditions, the combination of GD-OES and XPS techniques seems to be an easy and rapid way to obtain the in-depth quantitative chemical surface composition of the thin oxide layers deposited on the rough substrates. This particular approach on the type of analyzed system has never been demonstrated, to our knowledge.

The so-called shadowing effect of the surface roughness on the ion beam can be described by simple geometry [59]. The significant roughness of the analyzed sample can result in the zones less accessible for sputtering with the ion beam oriented $45^{\circ}$ to the surface and influence the shape of the crater. In some cases, with high micrometric substrate roughness, like the one shown in this work, the applicability of the ToF-SIMS to perform craters in which XPS is acquired could be questionable. This lateral homogeneity issue of the sputtering was previously observed in the case of ToF-SIMS imaging [60]. If the sputtering inhomogeneity is well described and considered, ToF-SIMS still offers interesting perspectives for localized sputtering and following localized analysis.

However, the induced roughness in the nanometer range was less significant after low angle ion beam from ToF-SIMS sputtering than after argon plasma sputtering by GD-OES, which is consistent with the literature [61]. An alternative solution to perform the in-depth quantitative chemical description on rough substrate would be to couple XPS with an in situ argon ion gun normal to the surface.

In addition, the development of the so called "ultra-fast sputtering" using argon-oxygen gas mixture in the plasma for GD-OES analysis has allowed to obtain fast sputtering of different types of materials with GD-OES, such as thin polymer coatings [62]. To some extent, the methodology proposed in this work could be used for a quantitative chemical description of the metallic surface at buried metal-polymer interfaces to follow a degradation of painted systems at different steps of ageing.

\section{Conclusions}

A methodological approach was proposed to obtain a chemical in-depth characterization of conversion coating on rough substrates by combining low energy argon plasma GD-OES sputtering or oxygen ion sputtering using ToF-SIMS with XPS and nanoprobe Auger electron microscopy characterizations. Homogeneously sputtered craters with nanometric depth were obtained. The 
chemical composition evolution during sputtering was very similar for both GD-OES and ToF-SIMS elemental in-depth profiles.

Auger electron microscopy was used to measure the local thickness of the remaining conversion coating after sputtering in different areas of the model craters. It was shown that due to the low incidence angle of the ToF-SIMS ion etching, the sputtering can be uneven for the rough samples like electrodeposited substrate. The sputtering performed by GD-OES argon plasma was much less influenced by the substrate roughness, showing a more homogeneous topography and chemistry inside the crater. This allows to propose GD-OES as an interesting tool for sample preparation prior to XPS analysis at buried interfaces, permitting a representative chemical characterization inside the crater.

For the studied $\mathrm{Cr}$ (III) conversion coatings deposited on $\mathrm{Zn}$ alloy substrate, a methodological approach using XPS characterization and data treatment of the $\mathrm{Cr} 2 \mathrm{p}$ core level peaks was proposed. It resides in the subtraction of the contribution of zinc Auger peaks in the $\mathrm{Cr} 2 \mathrm{p}$ region, allowing for a quantitative analysis of the surface chemistry of conversion coating composed of zinc and chromium.

High resolution XPS spectra were measured on the top surface of $\mathrm{Cr}(\mathrm{III})$ based conversion coating on rough $\mathrm{Zn}$ alloy substrate and in the sputtered craters near the coating/substrate interface. The XPS demonstrated that the coating is mainly composed of zinc hydroxides and $\mathrm{Cr}(\mathrm{III})$ species with an atomic $\mathrm{Zn} / \mathrm{Cr}$ ratio of 1.6. Interestingly, $\mathrm{Cr}$ to $\mathrm{Zn}$ ratio in the whole conversion coating depth (outer and inner part) was similar, demonstrating homogenous depth distribution of $\mathrm{Cr}$ species.

Finally, the coupling of XPS with GD-OES was shown to be an efficient methodology for the indepth chemical description of oxide layers on electrodeposited rough substrates. 


\section{References}

[1] T.J. Natorski, Zinc and zinc alloy plating in the 90s, Met. Finish. 90 (1992) 15-17.

[2] D.E. Hall, Electrodeposited zinc-nickel alloy coating: A review, Plat. Surf. Finish. 70 (1983) 59-65.

[3] M.S. Chandrasekar, S. Srinivasan, M. Pushpavanam, Properties of Zinc alloy electrodeposits produced from acid and alkaline electrolytes, J. Solid State Electr. 13 (2009) 781-789.

[4] T. Biestek, J. Weber, Electrolytic and chemical conversion coatings: a concise survey of their production, properties and testing, Electrolytic and Chemical Conversion Coatings, Redhill : Portcullis Press Ltd, 1976.

[5] A.S.H. Makhlouf, Current and advanced coating technologies for industrial applications, in:, A. S. H. Makhlouf, I. Tiginyanu (Eds.), Nanocoatings and Ultra-Thin Films, Woodhead Publishing Ltd. 2011.

[6] C.S. Jeffcoate, H.S. Isaacs, A.J. Aldykiewicz, M.P. Ryan, Chromate in conversion coatings: a XANES study of its concentration and mobility, J. Electrochem. Soc. 147 (2000) 540-547.

[7] U.S. EPA (1998) Principles of Environmental Impact Assessment Review: Appendix A: Environmental Impact Assessment Checklist.

[8] European Commission regulation report n²017/999 - REACH, Official Journal of European Union (2017)

[9] G.D. Wilcox, J.A. Wharton, A review of chromate-free passivation treatments for zinc and zinc alloys, T. I. Met. Finish. 75 (1997) B140-B142.

[10] G. Wilcox, Replacing chromates for the passivation of zinc surfaces, T. I. Met. Finish. 81 (2003) B13-B15.

[11] J.W. Bibber, Non-chrome-containing conversion coatings for zinc and zinc alloys: Environmentally friendly alternatives provide equal or better adhesion and corrosion resistance as conventional methods, Met. Finish. 106 (2008) 41-46.

[12] R. Berger, U. Bexell, T.M. Grehk, S.E. Hörnstörm, A comparative study of the corrosion protective properties of chromium and chromium free passivation methods, Surf. Coat. Tech. 202 (2007) 391-397.

[13] J.A. Wharton, G.D. Wilcox, K.R. Baldwin, Non-Chromate Conversion Coating Treatments For Electrodeposited Zinc-Nickel Alloys, Int. J. Surf. Eng. Coat. 74 (1996) 210-213.

[14] J.A. Wharton, G.D. Wilcox, K.R. Baldwin, An Electrochemical Evaluation of Possible Non-Chromate Conversion Coating Treatments for Electrodeposited Zinc-Nickel Alloys, Int. J. Surf. Eng. Coat. 77 (1999) 152158.

[15] K. Cho, V.S. Rao, H. Kwon, Microstructure and electrochemical characterization of trivalent chromium based conversion coating on zinc, Electrochim. Acta 52 (2007) 4449-4456.

[16] H.H Sheu, H.B. Lee, S.Y. Jian, C.Y. Hsu, C.Y. Lee, Investigation on the corrosion resistance of trivalent chromium conversion passivate on electroplated Zn-Ni alloy, Surf. Coat. Tech. 305 (2016) 241-248.

[17] X. Zhang, C. van den Bos, W.G. Sloof, A. Hovestad, H. Terryn, J.H.W. de Wit, Comparison of the morphology and corrosion performance of $\mathrm{Cr}(\mathrm{VI})$ - and $\mathrm{Cr}(\mathrm{III})$-based conversion coatings on zinc, Surf. Coat. Tech. 1999 (2005) 92-104.

[18] G. Greczynski, L. Hultman, X-ray photoelectron spectroscopy: Towards reliable binding energy referencing, Prog. Mater. Sci. 107 (2020) 100591.

[19] A.I. Stoica, J. Światowska, A. Romaine, F. Di Franco, J. Qi, D. Mercier, A. Seyeux, S. Zanna, P. Marcus, Influence of post-treatment time of trivalent chromium protection coating on aluminium alloy 2024-T3 on improved corrosion resistance, Surf. Coat. Tech. 369 (2019) 186-197.

[20] J.E. Devries, Surface Characterization methods - XPS, ToF-SIMS, and SAM a complementary ensemble of tools, J. Mat. Eng. Perf.7 (1998) 303-311.

[21] R.E. Galindo, R. Gago, D. Dudy, C. Palacio, Towards nanometric resolution in multilayer depth profiling: a comparative study of RBS, SIMS, XPS and GDOES, Anal. Bioanal. Chem. $386(2010$,$) 2725-2740.$

[22] S. Hamadi, M.-P. Bacos, M. Poulain, A. Seyeux, V. Maurice, P. Marcus, Oxidation resistance of a Zr-doped $\mathrm{NiAl}$ coating thermochemically deposited on a nickel-based superalloy, Surf. Coat. Tech. 204, 6-7, (2009) 756760.

[23] M. Ely, J. Światowska, A. Seyeux, S. Zanna, P. Marcus, Effect of Post-treatment on Improved Corrosion Behavior of Trivalent Chromium Protection (TCP) Coating Deposited on Aluminium Alloy 2024-T3, J. Electrochem. Soc. 164 (2017) C276-C284.

[24] E. Gardin, S. Zanna, A. Seyeux, A. Allion-Maurer, P. Marcus, XPS and ToF-SIMS characterization of the surface oxides on lean duplex stainless steel - Global and Local approaches, Corros. Sci. 155 (2019) 121-133.

[25] S.V. Baryshev, J.A. Klug, A.V. Zinovev, C.E. Tripa, Q. Peng, J.W. Elam, I.V. Veryovkin, Measuring the roughness of buried interfaces by sputter depth profiling, Nanotechnology 24 (2013) 015708. 
[26] D. Mercier, M. Bouttemy, J. Vigneron, P. Chapon, GD-OES and XPS coupling : A new way for the chemical profiling of photovoltaic absorbers, Appl. Surf. Sci. 347 (2015) 799-807.

[27] A. Loubat, S. Béchu, M. Bouttemy, C. Eypert, S. Gaiaschi, Mathieu Frégnaux, D. Aureau, J. Vigneron, N. Simon, P. Chapon, A.M. Gonçalves, A. Etcheberry, Coupling GD-OES and XPS profiling to perform advanced physico-chemical characterizations of III-V layers for photovoltaic applications, Conference WCPEC-7 (2018) 10.1109/PVSC.2018.8547731.

[28] T. Nelis, R. Payling, Glow Discharge Optical Emission Spectroscopy: A Practical Guide, Royal Society of Chemistry Cambridge, 2003.

[29] N. Trigoulet, T. Hashimoto, I.S. Molchan, P. Skeldon, G.E. Thompson, A. Tempez, P. Chapon, Surface topography effect on glow discharge depth profiling analysis, Surf. Interf. Anal. 42 (2010) 328-333.

[30] S. Hoffman, A. Zalar, Depth Profiling with Sample Rotation: Capabilities and Limitations, Surf. Interf. Anal. 21 (1994) 304-309.

[31] E.H Cirlin, Auger electron spectroscopy and secondary ion mass spectroscopy depth profiling with sample rotation, Thin Solid Films 220 (1992) 197-203.

[32] J. Karlsson, S.E. Hörnström, H. Klang, J.O. Nilsson, Sputter-induced effect on quantitative GD-OES depth profiles from hot-dip zinc-coated steel, Surf. Interf. Anal. 21 (1994) 365-369.

[33] R.E. Galindo, L. Vasquez, Dynamics of GDOES-induces surface roughening in metal interfaces, Anal. Biol. Chem. 406 (2014) 7483-7495.

[34] V. Hoffman, R. Dorka, L. Willken, V.D.Hodoroaba, K. Watzig, Present possibilities of thin-layer analysis by GDOES, Surf. Interf. Anal. 35 (2003) 575-582.

[35] C.C. Chang, Analytical Auger Electron Spectroscopy, Charact. Solid Surf. (1974) 509-575.

[36] E. Martinez, P. Yadav, M. Bouttemy, O. Renault, L. Borowik, F. Bertin, A. Etcheberry, A. Chabli, Scanning Auger microscopy for high lateral and depth elemental sensitivity, J. Electron Spectrosc. 191 (2013) 86-91.

[37] T.S. Sun, D.K. McNamara, J.S. Ahearn, J.M. Chen, B. Ditchek, J.D. Venables, Interpretation of AES depth profilies of porous Al anodic oxides, Appl. Surf. Sci. 5 (1980) 406-425.

[38] A. Berna, P.B. Barna, A. Zalar, Ion Beam Induced Roughness and its Effects in AES Depth Profiling of Multilayer Ni/Cr Thin Films, Surf. Interf. Anal. 12 (1988) 144-150.

[39] A.W. Czanderna, T.E. Madey, C.J. Powell, Beam effects, surface topography, and depth profiling in surface analysis, Methods of Surface Characterization, Springer Books, 2002.

[40] S.N. Raman, D.F. Paul, J.S. Hammond, K.D. Bomben, Auger electron spectroscopy and its application to nanotechnology, Microscopy Today 19 (2011) 12-15.

[41] Z. Gao, P. Banerjee, Review article: Atomic layer deposition of doped ZnO films, J. Vac. Sci. Technol. 37 (2019) 050802.

[42] Keyence Corporation (Osaka, JP) Three-dimensional image processing apparatus, three-dimensional image processing method, three-dimensional image processing program, computer-readable recording medium, and recording device, US Patent 9,756,314, issued September 5, 2017.

[43] D. Necas, P. Klapetek, Gwyddion: an open-source software for SPM data analysis, Cent. Eur. J. Phys. 10 (2012) 181-188.

[44] V. Maurice, H. Peng, L. Klein, A. Seyeux, S. Zanna, P. Marcus, Effects of molybdenum on the composition and nanoscale morphology of passivated austenitic stainless-steel surfaces, Faraday Discus. 180 (2015) 151170.

[45] J. F. Moulder, Handbook of X-ray Photoelectron Spectroscopy: A Reference Book of Standard Spectra for Identification and Interpretation of XPS Data, Physical Electronics Division, Perkin-Elmer Corporation, 1992.

[46] G. Deroubaix, P. Marcus, X-ray photoelectron spectroscopy analysis of copper and zinc oxides and sulphides, Surf. Interf. Anal. 18 (1992) 39-46.

[47] L.S. Drake, D.R. Baer, J.M. Zachara, Auger Parameter Measurements of Zinc Compounds Relevant to Zinc Transport in the Environment, Surf. Interf. Anal. 14 (1989) 71-75.

[48] M. C. Biesinger, L. W.M. Lau, A. R. Gerson, R. St.C. Smart, Resolving surface chemical states in XPS analysis of first row transition metals, oxides and hydroxides: Sc, Ti, V, Cu and Zn, Appl. Surf. Sci. 257 (2010) 887-898.

[49] A. E. Hughes, R. J. Taylor, B.R.W. Hinton, Chromate Conversion Coatings on 2024 Al Alloy, Surf. Interf. Anal. 25 (1997) 223-234.

[50] W. P. Yang, D. Costa, P. Marcus, Resistance to Pitting and Chemical Composition of Passive Films of Fe$17 \% \mathrm{Cr}$ Alloy in Chloride-Containing Acid Solution, J. Electrochem. Soc. 141 (1994) 2669.

[51] E. Cuynen, P.V. Espen, G. Goeminne, H. Terryn, On the structure and chemical composition of chromiumbased conversion coatings on aluminium: A ToF-SIMS Study, J. Anal. Atom. Spectrosc. 14 (1999) 483-486. 
[52] J.-T. Li, V. Maurice, J. Światowska-Mrowiecka, A. Seyeux , S. Zanna, L. Klein, S.-G. Sun, P. Marcus, XPS, Time-of-Flight-SIMS and Polarization Modulation IRRAS study of $\mathrm{Cr} 2 \mathrm{O} 3$ thin film materials as anode for lithium ion battery, Electrochim. Acta, 54 (2009) 3700-3707.

[53] R. Viroulaud, J. Światowska, A. Seyeux, S. Zanna, J. Tardelli, P. Marcus, Influence of Surface Pretreatments on the Quality of Trivalent Chromium Process Coatings on Aluminum Alloy, Appl. Surf. Sci. 423 (2017) 927-938.

[54] R. Ramanauskas, R. Juskenas, A. Kalinicenko, L.F. Garfias-Mesias, Microstructure and corrosion resistance of electrodeposited zinc coatings, J. Solid State Electrochem. 8 (2004) 416-421.

[55] P.J. Cumpson, Angle-resolved XPS and AES: depth-resolution limits and a general comparison of properties of depth-profile reconstruction methods, J. Electron Spectrosc. 73 (1995) 25-52.

[56] X. Zhang, C. van den Bos, W.G. Sloof, H. Terryn, A. Hovestad, J. H.W. de Wit, Investigation of $\mathrm{Cr}(\mathrm{III})$ based conversion coatings on electrogalvanized steel, Surf. Eng. 20 (2004) 244-250.

[57] T. Basu, D.P. Datta, T. Som, Transition from ripples to faceted structures under low-energy argon ion bombardment of silicon: understanding the role of shadowing and sputtering, Nanoscale Re. Lett. (2013) 289

[58] M. Küstner, W. Eckstein, V. Dose, J. Roth, The influence of surface roughness on the angular dependence of the sputter yield, Nucl. Instrum. Methods in Phys. Res. 145 (1998) 320-331.

[59] J.L.S. Lee, I.S. Gilmore, I.W. Fletcher, M.P. Seah, Topography and field effects in the quantitative analysis of conductive surfaces using ToF-SIMS, Appl. Surf. Sci. 255 (2008) 1560-1563.

[60] S. Rangarajan, B.J. Tyler, Topography in secondary ion mass spectroscopy images, Journal of Vacuum Science and Technology A: Vacuum, Surf. Films 24 (2006) 1730-1736.

[61] M. W. Thompson, Defects and Radiation Damage in Metals, Cambridge University Press, London, 1968.

[62] P. Chapon, A. Tempez, C. Olivero, T. Nakamura, H. Nakamura, A. Fujimoto, Procédé de mesure par spectrométrie de décharge luminescente d'un échantillon solide organique ou polymère, European Patent EP2434275A1, 2012. 